\title{
ANNUAL REPORT 1988
}

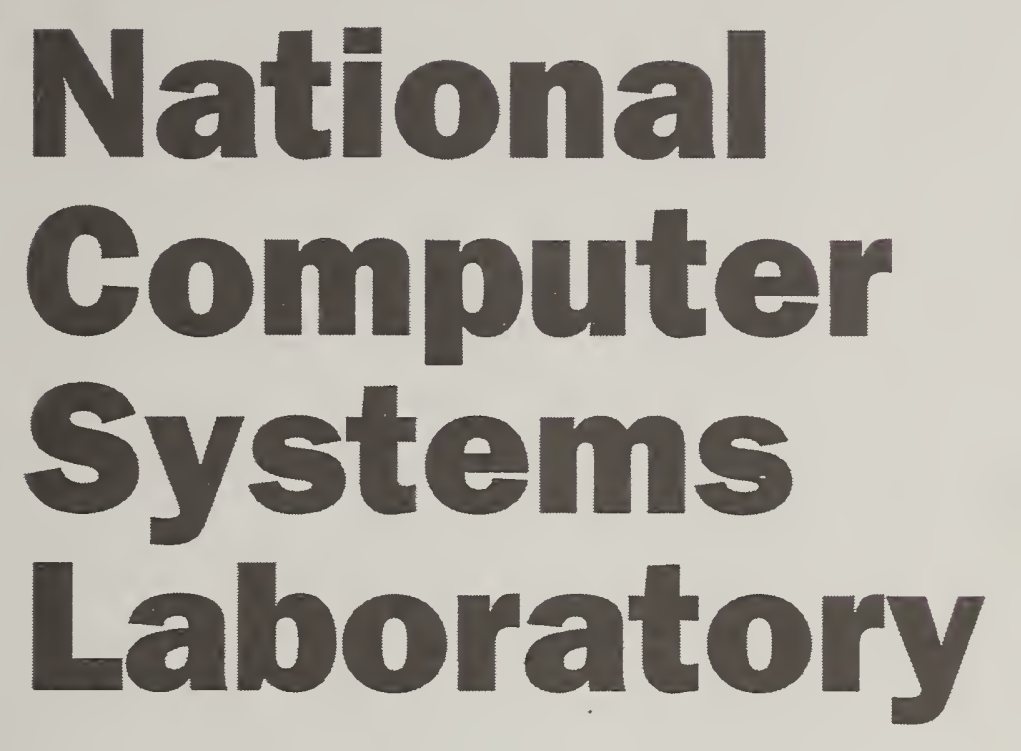

U.S. Department of Commerce

National Institute of Standards and Technology 



\section{ANNUAL REPORT \\ 1988}

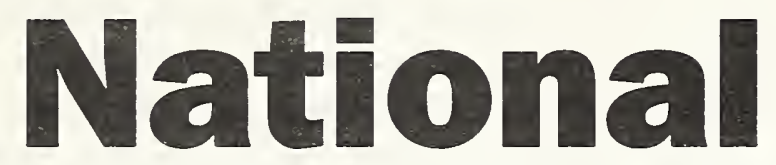

Computer

Systems
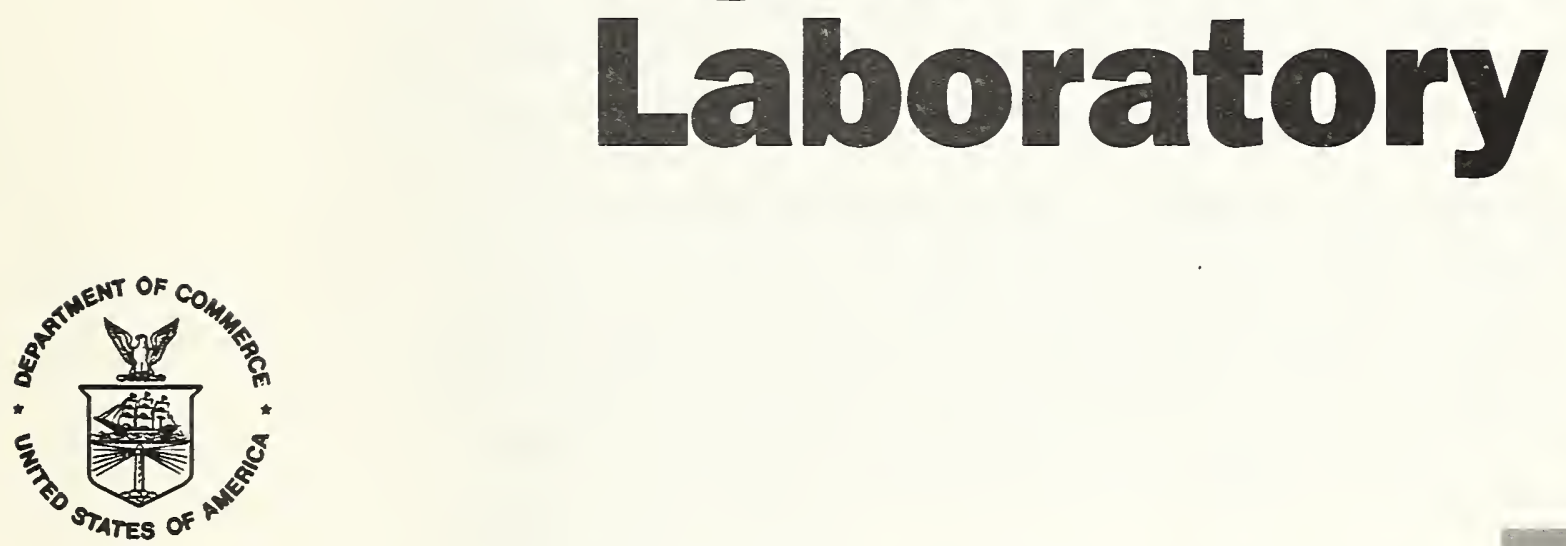

U.S. Department of Commerce

Robert A. Mosbacher, Secretary

National Institute of Standards and Technology Raymond G. Kammer, Acting Director

National Computer Systems Laboratory James H. Burrows, Director

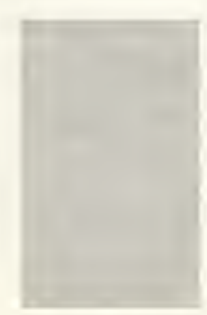





\section{DIRECTOR'S FOREWORD}

During the past year, the quest for computer system standards became a major force in the computer marketplace. New alliances and consortia were formed, restructuring the computer industry and stimulating a variety of "standard" solutions to pressing problems. Both vendors and users are promoting "open" systems that will allow computers manufactured by different vendors to communicate easily with one another and to use the same software.

Federal government requirements for open systems have been clear for many years. The Federal government carries out unique, complex, and critical information processing operations, and develops its computer systems in a competitive, multi-vendor environment. Standards are essential, both to achieve communication between different computers, and to manage multi-billion computer operations in a cost-effective way.

In 1988 the Secretary of Commerce approved two important Federal Information Processing Standards that will help the Federal government develop open systems -- the Government Open Systems Interconnection Profile (GOSIP), and the standard for Portable Operating System Interface for Computer Environments (POSIX). In developing these standards, NIST worked closely with vendors, users, and national and international standards organizations.

Off-the-shelf commercial products implementing the standards are now, or will soon be, available to meet both Federal government and private sector requirements.

While these standards are important building blocks of open systems, they alone are not enough to achieve integrated systems with common functions and common interfaces. GOSIP is based on standard data communications protocols and on implementation agreements reached by the NIST Workshop for Implementors of OSI. It supports electronic mail and file transfer functions. POSIX provides initial functions needed by users of UNLX-type operating systems. We are continuing to revise and to extend these standards, adding functions needed by users.

Additional standards, implementation agreements, and methods for testing for conformance will be needed as computer and communications technology changes. Telecommunications standards, for example, are essential for global exchange of voice, text, data, and images. The North American ISDN (Integrated Services Digital Network) Users Forum which we organized this year brings users and vendors of ISDN systems together to develop agreements needed to assure interoperable systems based on standards. The workshop has made an excellent start in defining user requirements for both the public and private sectors.

A comprehensive strategy based on standards will be essential for future government information processing activities. Taking the lead, the Department of Defense (DoD), for example, has adopted a systems architecture for its Computer-Aided Acquisition and Logistics Support (CALS) program. DoD plans to acquire technical data in digital form for weapon systems entering production in 1990 and beyond. Working with NIST and with industry, DoD has developed a framework of standards that support the automated interchange of technical information. 
We are developing the Applications Portability Profile (APP) as an overall systems architecture. The APP defines a system of non-proprietary standards for hardware, operating system software, utility software, data formats and representations, and programming languages. Systems based on the APP will be able to exchange information and share complex, expensive software. Our work during the past year in support of open systems is discussed in this report.

The new consortia and cooperative ventures that started this year are healthy signs that standards are part of the strategies of many users and vendors. Open systems will give users better control over their information system investments and will expand vendor markets for software and systems.

This past year marked the beginning of a new emphasis on computer security within the Federal government. The Computer Security Act of 1987 reaffirmed NIST responsibilities for developing standards and guidelines to protect the security and privacy of unclassified information processed by Federal computers. The legislation also established new requirements for agencies to develop computer security plans and to conduct computer security awareness training. Our initial efforts to implement the Act are discussed in this report.

We have had a very productive year, and are encouraged by the new interest in standards. While we are beginning to find solutions to information systems problems, many technical challenges must be addressed. Methods are needed for improved connectivity and interoperation of automated systems to enable organizations to put information technology to practical use and to increase productivity. At the same time, we must develop cost-effective methods for identifying and removing threats to the security and confidentiality of data, and to the availability of processing services.

It is clear that solutions cannot be only "government" solutions, but must be broadly based to benefit both government and industry.

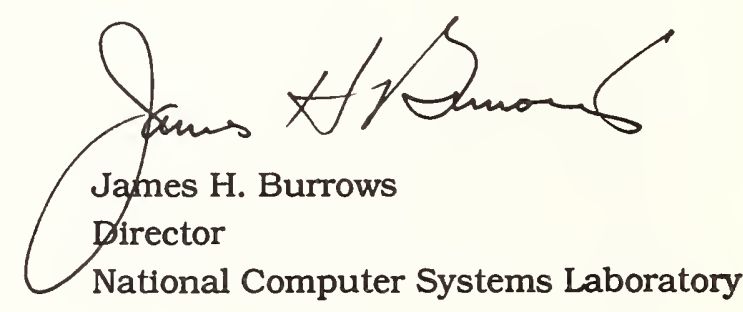




\section{CONTENTS}

OVERVIEW OF NATIONAL COMPUTER

SYSTEMS LABORATORY .............. 1

INFORMATION SYSTEMS ENGINEERING DIVISION . . . . . . .

SYSTEMS AND SOFTWARE TECHNOLOGY DIVISION . .

COMPUTER SECURITY DIVISION

\section{9}

SYSTEMS AND NETWORK ARCHITECTURE DIVISION

ADVANCED SYSTEMS DIVISION

TECHNICAL ASSISTANCE

\section{APPENDIX}

Organization Chart

Participation in Voluntary Standards Committees ....

NCSL Research Associates and Guest Scientists . . . .

Publications

30

Papers and Other Publications

Conferences and Workshops

Talks

\section{5}

Electronic Bulletin Boards 



\section{VERVIEW OF NATIONAL COMPUTER SYSTEMS LABORATORY}

The National Computer Systems Laboratory (NCSL) develops standards, provides technical assistance, and conducts research for computers and related telecommunications systems. The work of the Laboratory is carried out under authority of the Brooks Act (P.L. 89-306) and the Computer Security Act of 1987 (P.L. 100-235). NCSL's technical expertise and standards contributions support principal goals of the Department of Commerce to improve Federal government and private sector use of computer and telecommunications technology by increasing the reliability and capability to process information safely and correctly. The Computer Security Act strengthens and reaffirms NCSL's role in developing standards and guidelines to protect sensitive information in Federal computer systems. Specifically, the law assigns to NCSL a leadership role in computer security through research, the development of standards and guidelines, the establishment of security plans by operators of Federal computer systems, and mandatory periodic security awareness training in Federal agencies.

Organizationally, NCSL consists of five technical divisions: Information Systems Engineering Division, Systems and Software Technology Division, Computer Security Division, Systems and Network Architecture Division, and Advanced Systems Division. In FY1988, our staffing resources included 206 full-time-equivalent employees of which $75.7 \%$ were professional and technical staff and $24.3 \%$ were administrative support personnel. Most of our professional staff were computer scientists, computer specialists, electrical engineers, and mathematicians. In addition to our NIST staff, about 34 research associates, guest scientists, and faculty appointments were involved in collaborative research with NCSL.

Funding for FY1988 consisted of $\$ 9.0$ million from the NIST Congressional appropriation (STRS), including \$.9 million in NIST-supported competency funding; and \$11.5 million in reimbursable funds, mostly from other Federal agencies for direct technical assistance. NCSL provided reimbursable technical support to about 35 different organizations in government and industry. The Department of Defense, the Department of the Treasury, and the Internal Revenue Service are representative of the agencies which utilized the resources of NCSL to solve technical problems in computer security, hardware and software engineering, and the development of test procedures and methods.

Standards significantly enhance the effective and widespread use of computer technology by promoting the integration of hardware, software, and communication networks and by facilitating the exchange of information.

Standards are also essential for the protection of data from misuse or destruction; the current focus on computer security in government and industry promotes the development of standards for protecting access to and use of sensitive information.

NCSL continued to make major contributions to national and international standards development organizations to achieve these goals. Participation in voluntary industry standards-writing committees assures the development of standards that meet the requirements of the Federal government. Two major 
standards which foster the interoperabilty of systems and portability of computer applications were approved by the Secretary of Commerce as Federal Information Processing Standards (FIPS) this year. As a result of NCSL's contribution to the development of these standards, the Federal government will achieve increased flexibility and reduced costs in the future acquisition and use of computer systems.

To support the development of standards for complex systems, NCSL continued its emphasis on laboratory-based technical activities. The development of tests and measurement methods to evaluate the conformance of products to standards remained a high priority, as well as technology transfer and technical assistance projects. The implementation of the Computer Security Act of 1987 continued with several large conferences, published training guidelines, and the establishment of the Computer and Telecommunications Security (CTS) Council. The CTS Council is a joint industry/government forum to focus private and public sector efforts in seeking solutions to computer security problems.

The dissemination of information on computer and related telecommunications technology is an essential part of the NCSL mission. Standards and guidelines are published as FIPS. In 1988, approximately 25 new and revised FIPS were published as well as about 40 other reports. Included are 19 computer-related telecommunications standards now within the scope of NCSL as a result of the Computer Security Act of 1987. Fourteen computer-related telecommunications standards formerly the responsibility of the General Services Administration were redesignated as FIPS; five additional telecommunications standards were approved by the Secretary of Commerce this year. More than 120 FIPS and several hundred other reports are currently available to government and industry covering many aspects of computer utilization and standards implementation.

NCSL shares technology and information with government and industry through conferences, workshops, presentations, and briefings as well as publications. In 1988, NCSL presented workshops on computer security, the Portable Operating System Interface for Unix (POSLX) standard and the Applications Portability Profile (APP), and Open Systems Interconnection (OSI) as well as other relevant issues. Staff members participated in hundreds of talks and briefings to Federal officials as well as user groups (see the Appendix for details) and other professional societies.

Electronic bulletin boards are another means by which NCSL shares information with computer users with dial-up capabilities. NCSL operates electronic bulletin boards in the following areas: microcomputers and computer security; data management; Open System Interconnection standards; and Integrated Services Digital Network (ISDN). See the Appendix of this report for details on electronic bulletin boards.

Technical highlights of our Laboratory are described in the following sections of this report. 


\section{NFORMATION SYSTEMS ENGINEERING DIVISION}

The Information Systems Engineering Division works in the areas of data administration, data management technology, computer graphics, and software standards validation. As in past years, standards development activities and technical support for other Federal agencies were significant in 1988.

After eight years of support and assistance from NCSL, the Information Resource Dictionary System (IRDS) became an American National Standard in October when it received final approval from the American National Standards Institute (ANSI). The IRDS is a software system that records, stores, and processes information about an organization's data and data processing resources. The new standard will enable organizations to improve productivity by identifying information resources including computer programs that can be shared within the organization. IRDS is expected to be approved as a Federal. Information Processing Standard (FIPS) early in 1989.

NCSL released an updated and enhanced version of the IRDS prototype software which it developed. There are now over 90 users of this software in Federal agencies, private industry, academia, and several foreign countries. In March, NCSL conducted the FIPS Workshop on IRDS Applications, the eighth in a series of workshops for Federal agency personnel. In addition, NCSL finalized a Research Associate agreement with the Lawrence Berkeley Laboratory to further the development and practical utilization of the IRDS. Finally, NCSL established a formal working relationship with the Defense Logistics Agency to further the development of specifications and facilities to exchange information between information resource dictionaries.

Several IRDS documents were published in 1988, including A Technical Overview of the Information Resource Dictionary System (Second Edition) (NBSIR 883700) and Using the Information Resource Dictionary System Command Language (Second Edition) (NBSIR 88-3701). Also published was NBS Special Publication 500-152, Guide to Information Resource Dictionary System Applications: General Concepts and Strategic Systems Planning. This guide explains how an Information Resource Dictionary can be used to support information management activities throughout the life cycle of a system.

\section{Data Management Technology.}

To improve the use of data management technology, research focused on the development of programming languages, tools, and conformance tests for database systems. A distributed database management system is a collection of centralized database management systems that are connected via a communications network and integrated in their operations. As a result, collections of data can be used at various sites to support the database management system or other applications. The Guide to Distributed Database Management assists managers in evaluating distributed database management technology for their individual environments, and in planning for an orderly migration to distributed processing. Issued as NBS Special Publication 500-154, the guide discusses the characteristics of distributed database management systems, architectural alternatives, and the benefits, problems, and requirements for these systems. 
NCSL developed the first Structured Query Language (SQL) test suite to help users and vendors determine compliance with FIPS 127, Database Language SQL. The SQL test suite contains six different test types utilizing three programming languages: COBOL, Fortran, and C. First available to the public this year through a licensing arrangement with NCSL, the test suite may be obtained in various formats on magnetic tape and diskette.

A Knowledge-Based System for Physical Database Design reports on research in building a knowledge-based system for the solution of very difficult physical database design problems. Published as NBS Special Publication 500151 , the report describes a design system which processes large, multi-entity, logical database designs having complex workload requirements and identifies near-optimal designs for physical storage and access of the data. The system is implemented in Lisp.

NCSL completed a prototype expert system to select data sources from chemical information databases. An "Automated Advisor" conducts a dialogue with end-users and, based on their requirements, recommends a list of data sources from different chemical information databases. The system is described in detail in A Prototype Expert System: An Automated Advisor to Select Data Sources From Chemical Information Databases (NBSIR 88-3689).

Under an interagency agreement, NCSL assisted the National Archives and Records Administration in developing an Archives policy for the preservation of electronic records. Based on national and international standards, the policy addresses the efficient and reliable transfer of database information, graphics, text, and technical documents of historical value from the creating agencies to the National Archives for safekeeping and availability to historians.

Computer Graphics. NCSL continued to support the development and implementation of national and international standards in computer graphics. The Graphical Kernel System (GKS) was the first FIPS for computer graphics systems as well as being a national and international voluntary standard. A conformance test service was developed for GKS which determines if commercial implementations of GKS adhere to the standard. A contract was awarded to the National Computing Centre in the United Kingdom to perform on-site testing of GKS implementations.

Co-sponsored with Eurographics, NCSL hosted a meeting of twenty-five experts on graphics standards to discuss the impact of the computer graphics metafile (CGM) standard (FIPS 128) in a variety of environments. The meeting was the first in an international series to bring together graphics experts to discuss graphics standards. In addition, NCSL assisted 12 companies in preparing for the National Computer Graphics Association's Systems Integration Event held in March, 1988. Twelve different software systems were successfully demonstrated in NCSL's Computer Graphics Laboratory using the CGM standard.

The CGM application profile was updated for the Department of Defense's (DoD) Computer-Aided Acquisition and Logistic Support (CALS) project, an ongoing technical assistance effort. NCSL, and other units in NIST, continue to assist DoD in selecting and implementing the standards necessary to achieve a more reliable, cost-effective weapons system and supporting technical information. The standards have been published in MIL-STD-1840A, Automated 
Interchange of Technical Information. NCSL also developed a proposal to add CALS requirements to the national and international CGM standard.

To improve portability of graphics application programs among different manufacturers' computer systems, the Programmer's Hierarchical Interactive Graphics System (PHIGS) standard was approved and published as FIPS 153. PHIGS adopts a voluntary industry standard which specifies the control and data interchange between an application program and its graphics support system. The standard provides a set of functions and programming language bindings for the definition, display, and modification of two- or three-dimensional (3D) graphical data. NCSL also completed a design for a test suite to evaluate conformance of PHIGS implementations. Software Standards
Validation.
NCSL continued to provide validation services for testing compilers (programming language processors) for conformance to FIPS programming language standards and Federal Information Resources Management Regulations (FIRMR). Compilers which are tested and meet the FIPS and FIRMR requirements are issued a certificate of validation. Validation services are provided for COBOL (FIPS 21-2), Fortran (FIPS 69-1), BASIC (FIPS 68-1), Pascal (FIPS 109) and Ada (FIPS 119). During FY 1988, NCSL provided validation service to 42 private-sector companies and one Government agency, performing a total of 134 validations. The total number of compilers with a current validation certificate as of September 30, 1988 is 316 ; NCSL publishes a quarterly Certified Compiler List of compilers with validation certificates.

NCSL developed a proposed FIPS on Conformance Testing Policy and Procedures. The draft policy and procedures were discussed at the International Symposium on Testing for Conformance to Information Technology (IT) Standards held in May.

To facilitate the worldwide conformance testing effort, NCSL sponsored an International Workshop on Harmonizing Conformance Testing of Programming Language Standards. Experts from Japan, England, France, Germany, and the United States participated in the workshop. The participants represented conformance testing programs for the COBOL, Fortran, BASIC, Pascal, Ada, MUMPS, GKS, and SQL standards. The workshop focused on key issues surrounding mutual recognition of test methods, test reports, and validation certificates. 


\section{YSTEMS AND SOFTWARE TECHNOLOGY DIVISION}

Providing assistance to Federal consumers of commercial information system products and services is the goal of this Division; program areas covered were software engineering and office systems engineering. Technical activities of the Division during 1988 included the following:

\section{Portable Operating System Interface for Computer Environments (POSIX).}

For the past several years, NCSL has been working with vendors, users, and voluntary standards organizations to advance the implementation and use of the standard on Portable Operating System Interface for Computer Environments (POSIX). NCSL has been assisting the Institute of Electrical and Electronics Engineers (IEEE) in developing the standard, which has also been proposed as an international standard. Since POSIX promotes the portability of software applications, Federal agencies will benefit with reduced costs and increased flexibility when the standard is used in systems acquisition.

Issued as Federal Information Processing Standard (FIPS) 151, the POSLX standard was adopted on an interim basis to enable the Federal government to use the POSIX specification in procurements and in developing systems for applications portability. FIPS 151 adopts Draft 12 of the IEEE standard for POSIX. A FIPS adopting the final voluntary standard specifications for POSIX will be proposed when those specifications are completed.

As currently defined, POSLX is a crucial first step in providing a vendor-independent interface specification between an application program and an operating system. Additional interface specifications are needed to extend the POSIX standard to support source code portability for a wide range of applications across many different computer system architectures and operating systems. NCSL is supporting the development of these extensions in IEEE standards committees, and working with users and vendors to implement in products.

NCSL completed the development of the POSIX Conformance Test Suite (NBS-PCTS), a test suite that will be used to test conformance of operating system environments to the POSLX FIPS. Contributing to the development of the test suite were AT\&T, Hewlett Packard, IBM, Perennial, and X/OPEN who provided test suite source code for use as reference in building the test suite. NCSL is continuing to develop tests for functions in the extended POSIX standard, which will provide an interactive interface for users to control processing. IBM and Mindcraft, Inc. have assisted NCSL in this endeavor. The extended POSIX standard, along with other standards for advanced utilities, system administration, and terminal interfaces, will provide the broader functionality needed to support source code portability for a wide range of applications across many different systems.

Applications Portability Profile (APP).
The ability to move or port an application from one operating system environment to another is becoming increasingly important for cost-effective computing. In addition to a fully extended POSIX standard, there is a need for an architectural approach to applications portability. NCSL is working with industry and users to produce the needed specifications for both the extended POSIX and an Applications Portability Profile (APP). The APP will be a group of standard elements including database management, data interchange, network 
services, user interfaces, and programming languages. NCSL conducted three workshops in 1988 to discuss the APP and the POSIX standard; two additional workshops are planned for 1989.

\section{Electronic Publishing. sh}

Since its completion in October 1987, NCSL's Electronic Publishing Laboratory has been used to assist Federal agencies in the selection and use of publishing systems and to assess the capabilities and limitations of different publishing technologies. Equipment and software for the laboratory are loaned by the manufacturer; as new products become available, the laboratory configuration is changed to include these products. The laboratory's network configurations and processing systems range from personal computers and workstations to minicomputers, printing systems, and software tools for document preparation, publishing, and interchange.

In the past year, more than 300 visitors from government, industry, and foreign countries visited the facility for demonstrations of the multi-vendor electronic publishing systems. Laboratory demonstrations focus on electronic publishing and the role of standards in electronic document processing and interchange.

Office Document Exchange Standards.
NCSL continued to support the development of standards for the interchange of documents. Many years of collaboration with the International Organization for Standardization, Consultative Committee for International Telegraph and Telephone, European Computer Manufacturers Association, and other organizations led to development of the Standard Generalized Markup Language (SGML) and the Office Document Architecture (ODA) standards.

A FIPS approved this year by the Secretary of Commerce should help Federal agencies to improve their communications with publishing organizations. The new SGML standard provides a common way for defining markup languages so documents can be transferred from author to publisher in a standardized format. By providing a coherent and unambiguous syntax for describing the elements within a document, SGML promotes the portability of unformatted textual data among different installations and processing systems.

Developed by the International Organization for Standardization (ISO) and the American National Standards Institute (ANSI) with assistance from NCSL, the SGML standard is already being used by the Computer-Aided Acquisition and Logistics Support (CALS) program of the Department of Defense to develop a military specification. NCSL provides technical support for this endeavor. In addition, NCSL developed the first set of conformance tests for SGML; ISO and ANSI are considering using these tests for their own test suites.

NCSL collaborated on a project to define a testing methodology and tools for the ODA and Interchange Standard (ISO 8613). The National Computing Centre, United Kingdom, and the Department of Communications, Canada also contributed to the Testing ODA Conformance (TODAC) project. NCSL contributed to the development of the ODA standard which provides a logical structure for the content of an office document, enabling documents to be revised, processed, and interchanged without changing the structure.

A Document Application Profile (DAP) for the ODA standard was developed through the NIST Workshop for Implementors of OSI. The DAP is a functional 
subset of ODA that includes a conformance statement for ODA implementations and facilitates interoperability between ODA implementors.

Software NCSL published a new guideline which provides assistance to Federal agencies Maintenance. in improving the quality of the software that they acquire and develop. FIPS 132, Guideline for Software Verification and Validation Plans, adopts an ANSI/IEEE standard which NCSL helped to develop. The specifications provide uniform and minimum requirements for the format and content of software verification and validation plans. FIPS 132 will help agencies improve their software through early error detection and correction, enhanced reliability, improved management attention to the software process, improved assessment of proposed changes and their consequences, and improved user acceptance. In December, NCSL reported on the new guideline at a workshop on the NASA Software Assurance and Management Program, a program to assist NASA managers in acquiring large software systems that are safe, reliable, and easily maintained.

NCSL continued its support of FEDMAIN during 1988. FEDMAIN is an interagency user group for the exchange of information on software maintenance issues. At the eighth FEDMAIN Workshop held in January 1988, a new task force was formed for the assessment, selection, and support of software maintenance. Comprised of fourteen representatives of government, academic, and industry organizations, the task force initiated as its first project a survey of the FEDMAIN members' organizations to determine how software tools are used. More than 500 senior management officials and other software managers in the Federal government responded to the survey as well as counterparts in industry, state and local governments, and utilities. Results of the survey have been published as Assessment on the Selection. Acquisition, and Use of Software Maintenance Tools. The tool survey will help users make needed assessments to determine what tools are required and to evaluate the ability of these tools to satisfy stated requirements.

In March. NCSL contributed to COMPSTAN ' 88 which focused on the impact of standards on the development of computer technology and practice. A NCSL staff member chaired the conference, which was sponsored by the Institute of Electrical and Electronics Engineers. Papers, presentations, and panel sessions covered standards issues related to specific areas as well as general topics concerning the development, management, and use of standards.

Co-sponsored by NCSL and the Washington Chapter of the Association for Computing Machinery (ACM), the 27th Annual Technical Symposium was held in June, 1988. This year's theme was "Productivity: Progress, Prospects, and Payoff." Thirty-four speakers discussed software processes, tools, and standards. 


\section{OMPUTER SECURITY DIVISION}

In January, 1988, the Computer Security Act of 1987 became law. Much of the activity of the Division this year focused on implementing the new legislation and meeting requirements of the law in the following areas:

Training. NCSL worked closely with the Office of Personnel Management (OPM) to develop a regulation for the Federal government, which was issued on July 13, 1988 as 5 CFR Part 930. NCSL developed draft Computer Security Training Guidelines which describe which Federal employees require training and what training they should receive. The guidelines specify training content areas for specific target audiences including users, managers, and executives; training guides for these target audiences were developed and distributed at computer security workshops.

NCSL hosted two workshops designed to assist Federal agencies and contractor personnel to meet the requirements of the new law. In July, a one-day workshop cosponsored by NCSL, OPM, and the National Security Agency (NSA) focused on explaining provisions of the Computer Security Act. A two-day conference in October covered the implementation of training programs to improve computer security awareness as well as the development of computer security plans to protect systems that contain sensitive information.

Computer Security Plans.

Advisory Board.

Cooperative Industry/Government Activities.
The Computer Security Act specifies that Federal agencies must develop a computer security plan for each system that processes sensitive information and submit plans to NCSL and NSA for review by January 8, 1989. NCSL and NSA assisted the Office of Management and Budget (OMB)in developing Bulletin No. 88-16 which provides guidance on the preparation and submission of security plans. Detailed plans were formulated to establish a joint NCSL/NSA team to review the submitted plans.

As mandated by the legislation, NCSL established the Computer System Security and Privacy Advisory Board. The Board will identify technical, administrative, and physical safeguard issues in computer security, advise NIST and the Secretary of Commerce on privacy and security concerns in the Federal computing community, and report findings to OMB, NSA, and Congress. The membership of the advisory board will be selected according to guidelines in the Computer Security Act to achieve a balance between government and the private sector. An initial meeting is expected to be held in early 1989.

NCSL established a joint industry/government forum to focus private and public sector efforts in seeking solutions to computer security problems. The new Computer and Telecommunications Security (CTS) Council, composed of about 30 experts from the public and private sectors, seeks to improve existing technologies and to develop new strategies for protecting sensitive, important but unclassified information. The Council met initially in April; a second meeting in September refined issues and planned future activities. Work groups meet between Council meetings, develop studies and recommendations, and report back to the Council. Work groups address issues such as network security, data integrity, physical security, audit methods, and future technology. 
Technical Activities. Good risk management techniques are essential for carrying out the Computer Security Act's emphasis on "cost-effective" privacy and security. The risk management process enables computer users to analyze their information assets, threats, and vulnerabilities, to determine the measure of risk, and to select cost-effective safeguards for reducing the risks. NCSL's Risk Management Laboratory is used for research to improve tools, techniques, and guidance needed for risk management, and serves as a focal point for assisting Federal agencies in the selection and use of commercial risk management software. NCSL contributed to efforts to improve risk management methods through participation in the first Computer Security Risk Management Model Builders Workshop.

NCSL established a Secure Data Network System (SDNS) Protocol Laboratory to test and demonstrate network security protocols. SDNS was developed by the National Security Agency (NSA) in 1985. Based on the Open Systems Interconnection (OSI) computer network model, SDNS incorporates NSAdeveloped cryptography into two families of products. To date seven documents have resulted from the SDNS project specifying security services and protocols for user data as well as supportive services, including key management and access control. NSA released two of these documents to NCSL for use in its developmental activities in these areas. NCSL is considering reviewing and adopting SDNS security protocols as Federal Information Processing Standards (FIPS) as they become available for public review.

In response to a need produced by the widespread use of computers for activities such as payroll and accounts receivable, a guide to auditing the system development life cycle of an automated information system was issued as Special Publication 500-153, Guide to Auditing for Controls and Security: A System Development Life Cycle Approach. Developed in cooperation with the President's Council on Integrity and Efficiency (PCIE), the guide provides assistance to auditors, security reviewers, and quality assurance personnel in auditing a system for controls and security. The guide was developed over a four-year period with participation by auditing, security, and computer experts from government and the private sector.

A publication describing the validation system developed at NCSL to test message authentication devices for conformance to data authentication standards was issued this year. Special Publication 500-156, Message Authentication Code (MAC) Validation System: Requirements and Procedures, draws on work that was done for the Department of the Treasury. The MAC uses data encryption techniques to protect against accidental and intentional modification of data that is transmitted between computer systems. NCSL is assisting Treasury in using message authentication to protect electronic fund transfers.

Another publication completed this year is Special Publication 500-157. Smart Card Technology: New Methods for Computer Access Control. This research report describes the essential characteristics of smart cards and how these cards may be used to authenticate the users of modern computer networks. Smart cards with computation capabilities can be used in both user-tohost and host-to-user authentication processes. 
The Key Management Validation System (KMVS) developed by NCSL successfully validated a device for conformance to an industry standard for Financial Institution Key Management (Wholesale), ANSI X9.17. This standard gives rules and protocols for manual and automatic key distribution used for encryption and message authentication in point-to-point and key center environments. Developed under Department of the Treasury sponsorship over a two-year period, the KMVS tests the electronic distribution of keys in a point-to-point environment; the device was validated using a restricted set of options appropriate for Federal government use.

Standards Activities. This year NCSL continued to contribute to the development of voluntary industry standards for protecting financial data transmitted through networks. As in the past, the Division has actively participated in the work of the financial industry's standards committees.

The recent approval of FIPS 151 for POSIX (Portable Operating System Interface for Computer Environments) emphasizes the necessity for security features as new standards are developed. To help extend security controls to POSIX systems, NCSL has taken a leadership role in the voluntary standards committee (Institute of Electrical and Electronics Engineers P1003.6) that is developing POSIX security standards. 


\section{YSTEMS AND NETWORK ARCHITECTURE DIVISION}

NCSL continued its work with the public and private sectors in support of national and international standardization of Open Systems Interconnection (OSI). OSI networks permit equipment and systems from different manufacturers to interoperate. Major OSI developments in FY 1988 include:

GOSIP. The Secretary of Commerce approved the Government Open Systems Interconnection Profile (GOSIP) as Federal Information Processing Standard (FIPS) 146. GOSIP defines a common set of data communication protocols which enable systems developed by different vendors to interoperate and enable the users of different applications on these systems to exchange information. The new standard adopts OSI protocols which were developed by international standards organizations, primarily the International Organization for Standardization (ISO) and the Consultative Committee on International Telephone and Telegraph (CCITT). GOSIP is based on agreements reached by vendors and users of computer networks participating in the NIST Workshop for Implementors of OSI.

The NIST Workshop for Implementors of OSI met four times in 1988. The workshop is an open forum where implementors and users of OSI products reach specific agreements concerning the protocols, subsets, and options to be implemented. The workshop is organized as a set of special interest groups (SIGs) addressing such subjects as the lower and upper OSI layers, electronic mail, file transfer, virtual terminal, security, office document interchange, directory services, and network management. The output of this workshop is a documented set of agreements that facilitate the implementation of interoperable OSI products. Several groups have adopted the workshop output as the basis for functional profiles, including the Manufacturing Automation Protocol (MAP) and the Technical and Office Protocols (TOP). Workshop agreements are the second step in achieving compatible, interoperable products. The agreements follow the writing of the standards themselves. Testing of products for interoperability is also essential.

GOSIP will assist Federal government agencies in acquiring computer network and communications systems that support electronic mail and file transfer applications over a variety of local- and wide-area networks. The GOSIP standard will be required for the acquisition of products and services to be obtained in 1990. Technical implementation agreements for additional applications including virtual terminal, directory services, and transaction processing are under development for inclusion in future versions of GOSIP.

NCSL contributed to a major demonstration of computer system interconnectivdeveloped by different manufacturers exchanging information through networks based on OSI standards. NCSL staff members chaired technical sessions and presented technical papers as well as demonstrating a gateway processor system developed for the Department of Defense. 
OSINET. Established by NCSL, OSINET is a cooperative government/industry research network which is expediting the development and use of commercial OSI products. OSINET currently has 25 participants and nodes in California, Arizona, Minnesota, Michigan, Washington, Maryland, and Massachusetts, as well as the U.K., France, Spain, Sweden, and Australia. As the membership of OSINET expands, additional nodes will be established.

OSINET was used to test products for interoperability prior to their demonstration at the Enterprise Networking Event. The use of the network for remote testing of OSI protocols helped to save time and resources for the organizations taking part in the ENE. In preparing for earlier OSI demonstrations, participants had to gather in one place, and wait their turns to test against one another. OSINET participants were able to conduct interoperability tests with each other without leaving their offices. Although created primarily for vendor interoperability testing, OSINET was also used by government and private sector users to assess the applicability of OSI to the needs of their organizations, to monitor the progress of OSI products, and to acquire practical experience in using OSI technology.

Network Research and technical support activities centered on the identifying of Management. functional requirements of network management systems and supporting the development of standards for network management. As networks become large and complex, management of functions such as fault, configuration, accounting, performance, and security is a challenging technical task. Proprietary systems provide these tools for a single vendor's products, but not for multi-vendor open systems.

NCSL supported the development of network management standards by national and international standards organizations, and worked within the NIST Workshop for Implementors of OSI to develop interim solutions that fulfill both present and short-term future requirements for network management systems that can be used for multi-vendor networks.

Laboratory research focused on development, integration, and evaluation of network management services and protocols, and was supported in part by the Department of Defense. Research results were provided to standards writers, industry, and the OSI workshop to support the development of standards and appropriate workshop agreements.

Support for Other Federal Agencies.
Under contract to the Defense Communications Agency, NCSL completed Phase 1 of the OSI directory prototype implementation. These specifications are expected to be approved as international standards. Directory services protocols provide basic name to attribute mapping, searching, and browsing facilities for OSI networks. Connecting the prototype directory to the NCSLdeveloped Department of Defense (DoD)/OSI electronic mail gateway demonstrated the practical application of the protocols; this work will continue in 1989 as NCSL develops a strategy for the Department of Defense to make the transition to the OSI directory protocols. 
Funded by the Department of the Air Force, NCSL developed a draft statement entitled Directory Service Functional Requirements. Completed in May 1988, this document identifies the minimal requirements of directory services for inclusion into GOSIP. It has been distributed to a number of government agencies and other groups for information and comment.

The Defense Communications Agency and the Defense Advanced Research Projects Agency funded a cooperative project involving the University of California at Berkeley, the University of Wisconsin at Madison, IBM, the Wollongong Group, the MITRE Corporation, the University College London, and NCSL. The group is developing software to implement OSI protocols running on a POSIX conformant version of the Berkeley UNIX operating system. POSIX, the standard for Portable Operating System Computing Environments, is a standard interface to UNLX-like operating systems.

The software developed by the project will help organizations make the transition from DoD data communications protocols to OSI protocols which are based on international standards. The software includes file transfer, access, and management (FTAM), message handling systems (MHS), virtual terminal (VT), and directory services (DS) applications as well as a gateway allowing OSI and DoD file transfer and electronic mail users to interoperate. 


\section{DVANCED SYSTEMS DIVISION}

Activities in this Division focused on continued research in parallel processing performance, data storage technology, distributed systems, automated recognition methods including speech recognition, and Integrated Services Digital Networks (ISDN). Much of this research resulted from NCSL's continuing commitment to provide technical support to other Federal agencies.

Parallel Processing Performance Evaluation.

This work promotes the effective evaluation and efficient use of advanced multiprocessor computers by the Federal government. Investigations include exploring economical methods of instrumentation that perturb parallel processors very little, and designing coherent evaluations that reliably characterize the machines. As in past years, this effort was partially funded by the Defense Advanced Research Projects Agency (DARPA). Major accomplishments include the following:

Three NCSL researchers received the prestigious R\&D 100 award for the TRAce Measurement System (TRAMS). For use on a shared-memory multiprocessor, TRAMS is a hybrid measurement tool used to obtain trace measurement information. The TRAMS approach provides a hardware assist to the more traditional software approach to obtaining timestamps from the operating system at each event to be measured. This hardware assist reduces the artfact that is introduced in a test program and is a feasible and economical approach to providing measurement capabilities to a wide range of multiprocessors. Simllar pre-processor measurement instrumentation (LTRAMS) was also developed; this system has been applied to a 16-processor loosely coupled multiprocessor.

The Resource Measurement System (REMS) is a hardware measurement tool used to obtain both trace measurement and resource utilization information. The REMS approach provides more detailed measurement information than does the TRAMS approach and introduces no artifact to the test program, but it does this at a significantly higher cost. When access to pertinent signals is restricted, the applicability of such a hardware tool is limited.

Research results on these two approaches were published as NBSIR 873663, Recommended Instrumentation Approaches for a Shared-Memory Multiprocessor.

A report entitled Benchmarks to Supplant Export "FPDR" Calculations (NBSIR 88-3795) was completed for the Office of Export Administration in the Department of Commerce. NCSL investigated the feasibility of replacing certain formulas used in computer export evaluations with performances on actual benchmark codes. A committee of experts from several national laboratories and NCSL reviewed the measures used in export control and recommended replacement tests for those currently in use.

Data Storage. Established last year, the Federal CD-ROM (Compact Disk-Read Only Memory) technology evaluation laboratory provides a site where Federal users can evaluate $\mathrm{CD}-\mathrm{ROM}$ hardware and retrieval systems. More than $25 \mathrm{CD}-\mathrm{ROM}$ disks and 6 CD-ROM players have been installed; NCSL solicited disk and equipment donations for the laboratory from the private sector in collaboration with SIGCAT, a government-wide special interest group on CD-ROM technology. Other 
available CD-ROM databases include library catalogs, journal indexes, zip code directories, dictionaries, and product catalogs. CD-ROM drives and interfaces include systems manufactured by Phillips, Toshiba, Hitachi, and Sony.

Under an interagency agreement with the National Archives and Records Administration, NCSL is developing a testing methodology that can be used to predict life expectancy of optical disk media. This methodology was initially applied to evaluating different kinds of optical digital data disks; results of this research will assist government managers in planning how long information may be stored on optical disk media without significant deterioration. Also being studied is the standardization of test methods for measuring media characteristics and for predicting life expectancy of the media.

Partially supported by industry, research continued on the computer-controlled system for producing computer magnetic tape Standard Reference Materials (SRMs). The system was expanded to provide the overwrite, resolution, and peak shift tests needed for the new draft proposed standards for computer magnetic tape.

An OSI Workshop Implementors Agreement was completed for the Fiber Distributed Data Interface (FDDI), a 100-Mbit/s fiber optic local area network standard. In addition, a verification test script was prepared for FDDI Media Access Control (MAC) using a special programming language for verification tests called TTCN.

Distributed Systems. NCSL assisted the Internal Revenue Service (IRS) in developing the Citator Information System, a nationwide information retrieval system. In addition to completing an Analysis of Requirements for the system, NCSL designed the architecture for the system and developed a system prototype. NCSL is concurrently evaluating a prototype of the Automated Examination System Technical Architecture for the IRS. The Defense Logistics Agency (DLA) supported standards work on the Transaction Processing Protocol being done in subcommittees of the American National Standards Institute (ANSI) and the International Standards Organization (ISO). To assist this effort, NCSL contributed a 90page formal description of the protocol which was made an annex to the Draft Proposal for the protocol. DLA also supported standards work in the Open Distributed Processing Reference Model being done by ANSI and ISO with NCSL assistance.

Automated NCSL continued to support the Federal Bureau of Investigation (FBI) in developRecognition. ing standards for automated fingerprint identification systems (AFIS). A new standard for benchmarking the performance of AFIS was approved and published as ANSI/LAI 1-1988. The standard defines tests to measure the relative performance of AFIS. In the development of this standard, the canvass method was used to demonstrate consensus approval of interested parties. A glossary of automated fingerprint identification terms and acronyms is in the final approval process. The FBI is expected to adopt as its requirement a new draft standard for image quality of live-scan fingerprint images; studies on the performance of the FBI's fingerprint image scanner equipment were published as NBSIR 88-3831, AFRS Performance Evaluation Tests.

Sponsored in part by the Defense Advanced Research Projects Agency (DARPA), research in speech recognition technology continued in cooperation 
Integrated Services Digital Networks. with academia and the private sector. In 1988, NCSL initiated cooperative research programs with AT\&T Bell Laboratories and IBM involving sharing speech database material and evaluating the performance of state-of-the-art technology. NCSL's research involves the design and development of test procedures and other materials for the DARPA Speech Recognition Program. The test materials developed by NCSL are for use in evaluating the performance of speech recognition systems and include the development of speech database test materials and the use of an automated system for scoring speech software. Also developed were tests using a carefully specified test protocol.

NCSL continued its multi-year project to investigate standards and test methods for Integrated Services Digital Networks (ISDN). ISDN is a new telecommunications technology that makes it possible to send and receive voice, data, and image signals simultaneously over digital telephone networks. NCSL recently established the North American ISDN User's (NIU) Forum to create a strong user voice in the implementation of ISDN. The Forum consists of two workshops: one for ISDN users and one for ISDN implementors. The ISDN User's Workshop (IUW) identifies user applications for ISDN; the ISDN Implementor's Workshop (IIW) develops Application Profiles and Implementation Agreements to support IUW-defined Application Requirements. The IUW is organized into six industry groups: Manufacturing, Process, Service, Financial, Computing and Telecommunications, and Government. The IIW is organized into Working Groups (WGs) including an Applications Analysis WG, Application Demonstration and Promotion WG, Conformance Testing WG, and a number of expert WGs.

Initial meetings of the IUW and IIW focused on the development of procedures for processing Application Requirements, Application Profiles, and Implementation Agreements. A joint meeting of the IUW and IIW was held in September in St. Louis, MO with 100 users and 200 implementors attending. At this meeting the IUW formally approved 35 Application Requirements to submit to the IIW; these applications were sponsored by user organizations from government, industry, and academia.

NCSL signed Memoranda of Understanding with NYNEX and Bell Communications Research to cooperate in the development of conformance test methods for ISDN technology. These activities will support voluntary standards activities and the rapid introduction of standardized ISDN telecommunications products. The work is being carried out in cooperation with the Lower Layers Special Interest Group within the Workshop for Implementors of OSI. Activities to be conducted under the agreements include the development of ISDN conformance testing principles and methodology and the selection and implementation of approved national and international test suites suitable for ISDN. The conformance tests and testing methods are needed to assure interoperability of equipment implementing ISDN.

NCSL worked with the Department of the Navy (NAVDAC) to develop an ISDN evaluation and conformance testing laboratory. The current standards efforts have focused on narrowband ISDN, but are being expanded to cover broadband transmissions. 


\section{ECHNICAL ASSISTANCE}

In addition to the technical assistance projects discussed in division overviews, NCSL participated in the following activities:

궁 NCSL published the results of a study on computerized vote-tallying. Sponsored by the Markle Foundation of New York City, the study addresses potential inaccuracy or fraud in the vote-tallying process, the difficulty of verifying results, the possibility of undiscoverable fraud, and the lack of knowledge and resources of election officials. Accuracy. Integrity, and Security in Computerized Vote-Tallying (NBS Spec. Pub. 500-158) recommends that accepted practices of internal control be applied to vote-tallying. Other recommendations include the use of certified software, review of software for integrity and logical correctness, dedicated software use and dedicated operation, more accurate ballot reading, elimination of pre-scored punched card ballots, improved vote-tallying systems that do not use ballots, and improved pre-election testing and partial manual recounting of ballots.

At a Workshop on Computer Security in Vote-Tallying at the National Election Conference in September, the results of the vote-tallying study were presented to state, city, and county election officials. NCSL will continue its work in this area, focusing on the application of computers to assuring the accuracy of voter registration and the ballot formation process.

- NCSL continued its major technical assistance effort in support of the Department of Defense's (DoD) Computer-Alded Acquisition and Logistic Support (CALS) project. CALS is a concerted effort by DoD to automate the technical data used to support weapon systems throughout their life cycle. The goals of the program are reduced costs and more rapid exchange of technical information. NCSL assisted DoD in the identification, development, and implementation of CALS standards.

- A project sponsored by the National Archives and Records Administration led to the development of policies for the preservation of electronic records. Based on national and international standards, the policy recommendations are intended to facilitate the successful transfer of historical documents and databases from Federal agencies to the Archives for future reference and safekeeping. NCSL developed a draft Framework for the Transfer and Preservation of Electronic Records which relates the use of various software standards to the procedures and processes used by the National Archives in the preservation of the records of the Federal government. NCSL also developed a prototype software package that facilitates the standard transfer and storage of electronic documents prepared under different document preparation packages.

- A review of the Automated Patent System for the Patent and Trademark Office (PTO) was completed. Recommendations included improved planning for and implementation of hardware, software, and communications systems. The PTO has begun implementing recommendations to take full advantage of available technologies.

A plan was developed for the Naval Data Automation Command for naval base communications cable plants which support both voice telephone and digital data applications. 
- NCSL's Director served as a member of the General Services Administration's (GSA) Advisory Committee on the Federal Telecommunications System (FTS)2000 Procurement. The Committee was an important part of the process GSA has established to ensure that the selection of the FTS2000 contractors is fair to the companies competing for the government's business and that the government gets the best value for its money.

- The Director also reviewed agency computer and telecommunications plans, including those of the Department of the Interior and the Department of Defense. 

APPENDIX 



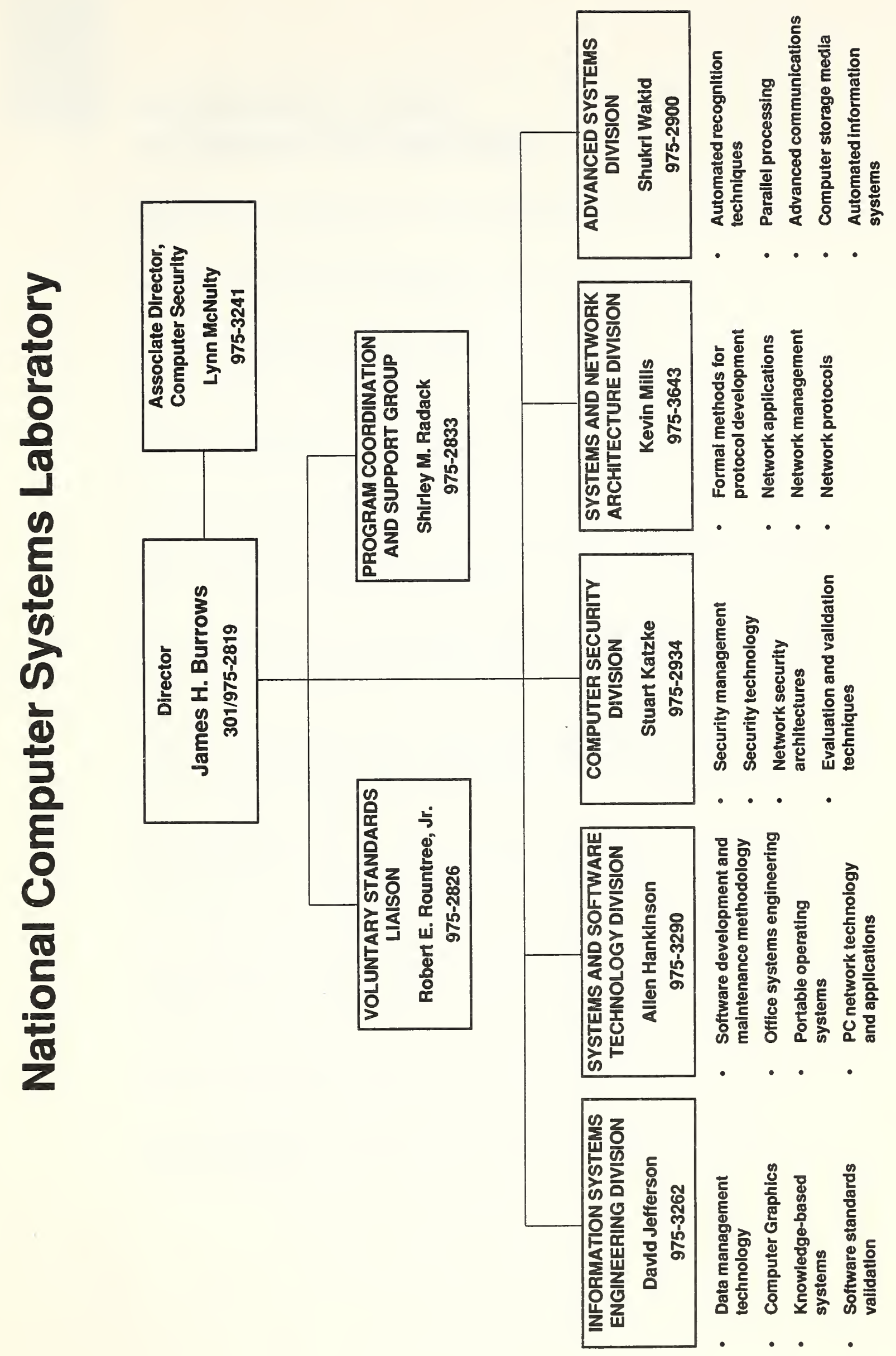





\section{SELECTED STAFF ACCOMPLISHMENTS}

Department of Commerce awards for major contributions to Department programs were presented to:

Robert J. Carpenter - Gold Medal

Anthony V. Cincotta - Bronze Medal

Dana S. Grubb - Bronze Medal

Frankie E. Spielman - Bronze Medal

Michael A. Wallace - Bronze Medal

Dennis Branstad chairs the special interest group on computer security for the NIST Workshop for Implementors of OSI.

James H. Burrows, Director of NCSL, has been appointed to the User Advisory Council of X/OPEN and to the Board of Directors of the Corporation for Open Systems.

Robert J. Carpenter, John W. Roberts, and Alan Mink received the R\&D 100 Award for the Trace Measurement System which helps measure the performance of multiprocessors.

Allen Hankinson, Chief of the Systems and Software Technology Division, chairs the IEEE P1003.0 working group developing standards for portability of applications software across heterogeneous computer architectures.

Robert Rountree has been elected Vice Chair of the JTC1 (Information Technology) Technical Advisory Group (TAG) to the American National Standards Institute.

Miles Smid chairs the Electronic Fund Transfers (EFT) Task Force subcommittee on cryptographic standards.

Dennis Steinauer chairs the IEEE P1003.6 working group developing POSIX security standards. 


\title{
PARTICIPATION IN VOLUNTARY STANDARDS COMMITTEES
}

NCSL staff members participate in more than 70 voluntary standards committees, including the following:

\author{
American National Standards Institute \\ Information Systems Standards Board (Chair) \\ T1 Telecommunications \\ X3 Information Processing Systems \\ International Advisory Committee \\ U.S. TAG for ISO/TC97/SC2 1 \\ U.S. TAG for ISO/TC97/SC22 \\ U.S. TAG for ISO/TC97/SC7 \\ Standards Planning and Requirements Committee \\ Database System Study Group
}

\author{
ANSI/X3 technical committees for: \\ Data communications \\ Open systems interconnection \\ Computer graphics \\ COBOL \\ Data representation \\ Information resource and dictionary system \\ Digital magnetic tape \\ Flexible cartridges disk \\ Codes and character sets \\ Optical digital data disk \\ I/O Interface \\ Office systems \\ Database \\ Common Lisp \\ Integrated circuit cards \\ Data exchange \\ Text office and publishing systems \\ Credit and ID cards \\ Office and publishing systems
}

ANSI/X9 Technical Committee for Financial Systems 
International Organization for Standardization technical committees for:

Text and office systems

Open systems interconnection

Optical digital data disk

Flexible magnetic media

Interconnection of equipment

Micrographics

Languages

Telecommunications and information exchange between systems

Institute for Electrical and Electronics Engineers

Standards Activities Board

Local area network standards

Operating systems

Operating systems interfaces

Computer Society Standards Activities Board

Portable operating system interface for computer environments (POSLX)

Software Engineering Standards

Software reliability

Software maintenance

Configuration management

Software quality metrics

Software validation, verification, and testing

Software lifecycle processes

Software acquisition

Association of Information and Image Management

Conference on Data Systems Languages

European Computer Manufacturers Association technical committees

Exchange Carriers Standards Association

Federal COBOL Interpretations Committee

Federal Interagency Coordinating Committee on Digital Cartography

Federal Telecommunications Standards Committee 
International Association for Identification

National Association of Photographic Manufacturers

U.S. Board on Geographic Names

Consultative Committee on International Telegraph and Telephone

technical committee

Data Communications Networks

NCSL staff members hold positions as officers, international representatives, and technical advisors in 19 committees. 


\section{NCSL RESEARCH ASSOCIATES AND GUEST SCIENTISTS FY 1988}

Guest Scientists and Research Associates 26

Organizations represented include:

Bell Communications Research

Digital Equipment Corp.

Institut National De Telecommunication, France

Institut De La Communication Parlee, France

Institute for Labour Hygiene, China

Institute for Computer Technology Academia Sinica, China

International Business Machines

International Computers Ltd., England

Jiaotong University, China

Manager Software Products

Mexico State University

Mindcraft

Nippon Telegraph \& Telephone Corp., Japan

Northeast University, China

People's Republic of China

Post-Telecommunications Science Research Institute, China

Tsinghua University, China

Untversity of Bordeaux, France

Yanghee Chol, Korea

Faculty Appointments

Georgetown University

Stevens Institute of Technology

University of Delaware

University of Maryland

University of Pittsburgh at Johnstown 


\section{COMPUTER SCIENCE AND TECHNOLOGY SERIES FY1986 - FY1988}

NBS SPEC. PUB. TITLE

500-128 Starting and Operating a Microcomputer Support Center By Ted Landberg and Stanley Winkler SN 003-003-02683-2 \$1.75 Oct 1985

500-129 Software Maintenance Management By James A. McCall, Mary A. Herndon and Wilma M. Osborne SN 003-003-02681-6 \$2.75 Oct 1985

500-130 Executive Guide to Software Maintenance By Wilma M. Osborne SN 003-003-02685-9 \$1.00 Oct 1985

500-131 Guide for Selecting Microcomputer Data Management Software By Charles Sheppard SN 003-003-02682-4 \$2.50 Oct 1985

500-132 Benchmark Analysis of Database Architectures: A Case Study Daniel R. Benigni, Editor SN 003-003-02684-1 \$7.50 Oct 1985

500-133 Technology Assessment: Methods for Measuring the Level of Computer Security By William Neugent, John Gilligan, Lance Hoffman, and Zella G. Ruthberg SN 003-003-02686-7 \$8.00 Oct 1985

500-134 Guide on Selecting ADP Backup Processing Alternatives

By Irene Isaac

SN 003-003-02701-4 \$1.75 Nov 1985

500-135 Integrated Software for Microcomputer Systems

By Lynne S. Rosenthal

SN 003-003-02711-1 \$1.75 Jan 1986

500-136 An Overview of Acceptance Testing of Computer Software

By Dolores Wallace

SN 003-003-02712-0 \$1.00 Feb 1986

SN numbers - stocked by GPO

PB numbers - stocked by NTIS 
NBS SPEC. PUB. TTTLE

500-137 Security for Dial-Up Lines

By Eugene F. Troy

PB $213097 \$ 13.95$ Jul 1986

500-138 A Functional Model for Fourth Generation Languages

By Gary Fisher

SN 003-003-02731-6 \$2.25 Jun 1986

500-139 Data Base Directions Information Resource Management -- Making It Work Elizabeth Fong and Alan Goldfine, Editors

SN 003-003-02738-3 \$9.00 Jun 1986

500-140 Personal Computer Networks

By John Barkley

SN 003-003-02746-4 \$3.25 Jul 1986

500-141 Annotated Bibliography on Sofiware Maintenance

By Wilma M. Osborne and Ron Raigrodski

SN 003-003-02756-1 \$6.50 Sep 1986

500-142 A Management Overview of Software Reuse

By William Wong

SN 003-003-02757-0 \$1.50 Sep 1986

500-143 Guide to the Selection and Use of Fourth Generation Languages

By Martha M. Gray

SN 003-003-02758-8 \$3.25 Sep 1986

500-144 Guidance on Software Package Selection

Edited by Sheila Frankel

SN 003-003-02773-1 \$6.00 Nov 1986

500-145 Programming Languages for Knowledge-Based Systems

By John V. Cugini

SN 003-003-02783-9 \$4.00 Feb 1987

500-146 Report on the NBS Software Acceptance Test Workshop

April 1-2, 1986

By Dolores R. Wallace and John C. Cherniavsky

SN 003-003-02793-6 \$2.75 Mar 1987

SN numbers - stocked by GPO

PB numbers - stocked by NTIS 
NBS SPEC. PUB. TITLE

500-147 Guidance on Requirements Analysis for Office Automation Systems (Update) By Lynne S. Rosenthal, Elizabeth G. Parker, Ted Landberg, and Shirley Ward Watkins SN 003-003-02791-0 \$5.50 Mar 1987

500-148 Application Software Prototyping and Fourth Generation Languages By Gary Fisher

SN 003-003-02797-9 \$3.25 May 1987

500-149 Guide on Data Entity Naming Conventions By Judith Newton SN 003-003-02818-5 \$3.00 Oct 1987

500-150 Stable Implementation Agreements for Open Systems Interconnection Protocols Version Edition 1

Workshop Chairman, Robert Rosenthal

PB 88-168331 \$24.95 Dec 1987

500-151 A Knowledge-Based System for Physical Database Design By Christopher E. Dabrowski and David K. Jefferson SN 003-003-02849-5 \$3.25 Apr 1988

500-152 Guide to Information Resource Dictionary Applications: General Concepts and Strategic Systems Planning By Margaret $\mathrm{H}$. Law SN 003-003-02865-7 \$8.00 Apr 1988

500-153 Guide to Auditing for Controls and Securlty: A System Development Life Cycle Approach

Editor/Authors Zella G. Ruthberg, Bonnie Fisher-Wright, William E. Perry, John Lainhart, James G. Cox, Mark Gillen, Douglas B. Hunt

SN 003-003-02856-8 \$13.00 Apr 1988

500-154 Guide to Distributed Database Management

By Elizabeth N. Fong and Bruce Rosen

SN 003-003-02848-7 \$1.75 Apr 1988

500-155 Management Guide to Software Reuse

By William Wong SN 003-003-02858-4 \$2.0 OApr 1988

SN numbers - stocked by GPO

PB numbers - stocked by NTIS 
NBS SPEC. PUB. TITLE

500-156 Message Authentication Code (MAC) Validation System: Requirements and Procedures

By Miles Smid, Elaine Barker, David Balenson, and Martha Haykin

SN 003-003-02860-6 \$2.75 May 1988

500-157 Smart Card Technology: New Methods for Computer Access Control By Martha E. Haykin and Robert B. J. Warnar

SN 003-003-02887-8 \$2.75 Sept 1988

500-158 Accuracy, Integrity, and Security in Computerized Vote-Tallying

By Roy G. Saltman

SN 003-003-02883-5 \$7.50 Aug 1988

500-159 Data Administration: Management and Practice - Proceedings of the First DAMA Symposium

Judith J. Newton and Frankie E. Spielman, Editors

Available from GPO Oct 1988

SN numbers - stocked by GPO

PB numbers - stocked by NTIS 


\section{OTHER NBS PUBLICATIONS FY 1987 - FY 1988}

PUB. NUMBER TITLE

NBSIR 87-3516 Workshop on Factory Communications

By Robert Rosenthal

April 1987 Order from NTIS

NBSIR 87-3536 A Methodology for Broadband Token Passing Bus Interoperability Testing By Robert Rosenthal and Dan Stokesberry

April 1987 PB 87-195327 \$11.95

NBSIR 87-3559 Annotated Bibliography on Reliable System Design

By W. McCoy, K. M. Roessing, and M. K. Ruhl

May 1987 PB 88-109848 \$18.95

NBSIR 87-3566 Final NBS Report for CALS, FY86

By Sharon Kemmerer

May 1987 PB 88-11394 \$42.95

NBSIR87-3568 On the Measurement of Fault-Tolerant Parallel Processors

By J. W. Roberts, A. Mink, and R. J. Carpenter

June 1987 PB 87-208328 \$11.95

NBSIR 87-3580 On Parallel Processing Benchmarks

By Gordon Lyon

June 1987 Order from NTIS

NBSIR 87-3585 Hardware-Assisted Multiprocessor Performance Measurements

By A. Mink, J. M. Draper, J. W. Roberts, R. J. Carpenter

June 1987 PB 87-226908 \$9.95

NBSIR 87-3593 A Survey of OSI Network Management Standards Activilites (USAF)

By C. M. Chernick, K. Mills, R. Aronoff, J. Strauch

June 1987 PB 88-110036 \$13.95

NBSIR 87-3627 ICST-Performance Measurement Instrumentation for Multiprocessor Computers

By R. J. Carpenter

August 1987 PB 88-112313 \$11.95

SN numbers - stocked by GPO

PB numbers - stocked by NTIS 
PUB. NUMBER TITLE

NBSIR 87-3663 Recommended Instrumentation Approaches for A Shared-Memory Multiprocessor By G. Nacht and A. Mink

October 1987 PB 88-164025

NBSIR 87-3674 Draft Stable Implementation Agreements for Open System Interconnection By Robert Rosenthal January 1988 PB 88-153333 \$12.95

NBSIR 88-3689 A Prototype Expert System: An Automated Advisor to Select Data Sources From Chemical Information Databases

By Elizabeth N. Fong and Christopher Dabrowski

January 1988 PB 88-164173 \$12.95

NBSIR 88-3700 A Technical Overview of the Information Resource Dictionary System

(Second Edition)

By Alan Goldfine and Patricia Konig

February 1988 PB 88-163779 \$19.95

NBSIR 88-3701 Using the Information Resource Dictionary System Command Language (Second Edition)

By Alan Goldfine

February 1988 PB 88-169545 \$14.95

NBSIR 88-3709 Reference Model for DBMS User Facility

By Elizabeth Fong

February 1988 PB 88-169446 \$12.95

NBSIR 88-3726 A Collection of Technical Studies Completed for the Computer-Aided Acquisition and Logistic Support (CALS) Program -- Fiscal Year 1987, (Vol. 1 of 4)

Sharon J. Kemmerer, Editor

March 1988 PB 88-192752 \$38.95

NBSIR 88-3727 A Collection of Technical Studies Completed for the Computer-Aided Acquisition and Logistic Support (CALS) Program -- Fiscal Year 1987, (VoL. 2 of 4)

Sharon J. Kemmerer, Editor

March 1988 PB 88-192760 \$38.95 


\section{PUB. NUMBER TITLE}

NBSIR 88-3768 Standards Conformance Testing: Issues and Activities Sharon J. Kemmerer, Editor

June 1988 PB 88-215645 \$14.95

NBSIR 88-3795 Benchmarks to Supplant Export "FPDR" Calculations

By Gordon Lyon

July 1988 PB 88-222864 \$12.95

NBSIR 88-3823 Ongoing Implementation Agreements for Open Systems Interconnection Protocols Volume 1: Stable Virtual Terminal \& Document Architecture and Interchange Format

Robert Rosenthal, Editor

July 1988 PB 88-243183 \$19.95

NBSIR 88-3824 Ongoing Implementation Agreements for Open Systems Interconnection Protocols Voloume 2: Continuing Agreements

Robert Rosenthal, Editor

July 1988 PB 88-243175 \$14.95

NBSIR 88-3830 The ICST-NBS Information Resource Dictionary System Command Language Prototype

By Alan Goldfine and Thomasin Kirkendall

August 1988 PB 88-243159\$14.95

NBSIR 88-3831 AFRS Performance Evaluation Tests

By R. T. Moore, R. M. McCabe, and R. A. Wilkinson

August 1988

Available from Advanced Systems Division 


\section{PAPERS AND OTHER PUBLICATIONS}

September 1987 through October 1988

Favreau, J.P., Linn, R. J., Garguilo, J.G. Lindley, L. A Test System for Implementations of MHS/SMTP Gateways, Final Report, Report No. ICST/SNA 87-5, Parts 1-3, September 1987.

Osborne, Wilma, M. Building and Sustaining Software Maintainability. IEEE Computer Society Press, pp. 13-23, October 1987.

Strausser, B., Favreau, J.P., et.al. Users Guide for the NBS Prototype Compiler for Estelle, Report No. ICST/SNA 87-3, October 1987.

Strausser, B., Favreau, J.P., et.al. Internal Guide for the NBS Prototype Computer for Estelle, Report No. ICST/SNA 87-4, October 1987.

Osborne, Wilma, M. Sustalning Software Maintainability. Computer Programming Management, Auerbach Publisher, November 1987.

Osborne, Wilma, M. Bullding Maintainable Software. Computer Programming Management, Auerbach Publisher, November 1987.

Newton, Judith. Designing Data Entity Naming Conventions. Proceedings of the Sixth International Conference on Entity-Relationship Approach, November 1987.

Bagg, Thomas C. Digitizing Documents: Guideline for Image Guality. Inform, November 1987.

Tang, D., Anzenberger, M., Wallace, M., and Markovitz, Paul. A Gateway Between MHS (X.400) and SMTP, December 1987.

Linn, Richard J., Favreau, Jean-Philippe and Iwabuchi, Akira. Application of Formal Specification Techniques to the Speciflcation of MHS Test System. Second International Symposium on Interoperable Information Systems (ISIS '88) - Japan, January 1988.

Linn, R. J., Favreau, J.P., Gebase, L., Iwabuch1, A. An Overview of Formally Specifled Multi-Layered Test Systems, Report No. ICST/SNA 88-1, (Presented to ANSI X3T5.1), January 1988.

Lyon, Gordon. A Tagless Marking That Is Linear Over Subtrees. Information Processing Letters, Vol. 27, No. 1, pp. 23-28, February 1988. 
Colella, Richard P., Fox, James F., Berrocal, J., and Vazquez, Enrique. Performance of OSI Transport over ACCUNET and IBERPAC. IEEE INFOCOM '88, Conference on Computer, Communications, March 1988.

Moore, Raymond T. American National Standard for Forensic Identification - Automated Fingerprint Identification Systems - Bench Mark Tests of Relative Performance. American National Standard, March 1988.

Linn, Richard J., and Favreau, Jean-Philippe. Application of Formal Description Techniques to the Specification of Distributed Test Systems. Proceedings of the IEEE INFOCOM '88 Conference, March 1988.

Wallace, Dolores R. and Daughtrey, Tez. Verifying and Validating for Maintainability. Proceedings from IEEE Computer Standards Conference, COMPSTAN'88, IEEE Computer Society Press, March 1988.

Heatley, Sharon, and Stokesberry, Dan. Measurements of a Transport Implementation Running Over an IEEE 802.3 Local Area Network. Computer Networking Symposium, Washington, DC, April 11-13, 1988.

Katzke, Stuart. A Small Business Guide to Computer Security. Available from the U.S. Small Business Administration, May 1988.

Smid, Miles E., and Branstad, Dennis K. The Data Encryption Standard: Past and Future. Proceedings of the IEEE Special Section on Cryptology, May 1988.

Burr, William E. and Zuqiu, Liu. An Overview of FDDI. EFOC/LAN '88, Amsterdam, June 1988.

Osborne, Wilma, M. Using Software Metrics and Measurement to Improve Software Productivity and Quality. Computer Standards Conference Proceedings '88, IEEE Computer Security Press, June 1988.

Wallace, Dolores R. Verification and Validation for Computer Assurance. Proceedings from COMPASS '88, June 1988.

Radack, Shirley M. U.S. Government Moves Toward Implementing OSI Standards. Computer, June 1988.

Mills, Kevin L. Government Open Systems Interconnection: Profile in Progress. The Technology Strategies '88 Conference (ISEC), July 1988.

Law, Margaret H. Significance of IRDS Standard for CASE. Proceedings of the Second Annual Workshop for Computer-Aided Software Engineering, CASE '88, Cambridge, MA, July 12-15, 1988. 
Tom, Henry. Standards: A Cardinal Direction for Geographic Information Systems. Papers from the 1988 Urban Regional Information Systems Association August 6-10, 1988.

Fong, Elizabeth N. and Dabrowski, Christopher E. Application of Expert System to Select Data Sources from Chemical Information Databases. Proceeding of ASME Computer in Engineering Conference, August 1988.

Nacht, George and Mink, Alan. Hardware Instrumentation Approach for Performance Measurement of a Shared-Memory Multiprocessor. Fourth International Conference on Modelling Techniques and Tools for Computer Performance Evaluation, Vol. II, pp 321-337, September 1988.

Gaudette, P., Truss, S. and Colins, Sarah. An Object-Oriented Model for ASN.1. Proceedings of the Eighth International Symposium on Protocol Specification, Testing and Verification, September 1988.

Sijelmassi, Rachid and Gaudette, Philip. An Object-Oriented Model for Estelle. Proceedings of FORTE 88, International Conference on Formal Description Techniques, September 1988.

Pallett, David S. Scoring Continuous Speech in the DARPA Speech Recognition Program: Part I. Proceedings of Military Speech Tech '88, September 13-17, 1988.

Linn, R. J., Favreau, J. P., Gaudette, P. Application of Formal Description Techniques to Conformance Evaluation. Proceedings of the FORTE ' 88 (also Report No. ICST/SNA 88-3), North Holland Publishing, Amsterdam, September 1988.

Kuhn, Richard. Static Analysis Tools for Software Security Certification. Proceedings of National Computer Security Conference, October 1988.

Pallett, David S. Scoring Continuous Speech in the DARPA Speech Recognition Program: Part II. Proceedings of AVIOS '88: American Voice Input/Output Society Conference, October 3-8, 1988.

Osborne, Wilma, M. Software Maintenance - A Mini-Tutorial. IEEE Computer Society Press, October 1988.

Saltman, Roy G. Accuracy, Integrity and Security in Computerized VoteTallying. Communications of ACM, V31, N10, pp. 1184-1191, 1218, October 1988.

Favreau, J. P., Linn, R. J., Garguilo, J. G., Lindley, J. A Test System for Implementations of FTAM/FTP Gateways, Final Report, Report No.

ICST/SNA 88-6, Parts 1-3, October 1988. 
Polk, W. T. Expert Assistance for Manipulation of Standard Generalized Markup Language (SGML). ACM (Association of Computing Machinery) Conference on Document Processing Systems, December 5-9, 1988

Moline, Judi. A Document Processing Model Using International Standards. Proceedings of ACM Conference on Document Processing Systems, December 1988.

Gaudette, P., Truss, S., Colins, S. ASN.1 Free Value Tool, Report No. ICST/SNA 88-2, December 1988.

Mink, Alan, Draper, Jesse M., Roberts, John W. and Carpenter, Robert J. Hardware-Assisted Multiprocessor Performance Measurements. Performance '87, P. J. Courtois and G. Latouche (editors), Elsevier Sclence Publishers B.V. (North-Holland), pp. 151-168, 1988.

Lyon, Gordon. Design Factors for Parallel Processing Benchmarks. International Symposium on High Performance Computer Systems, E. Gelenbe (ed1tor), Elsevier Science Publishers B.V. (North-Holland), pp. 103-114, 1988.

Carpenter, Robert J. Performance Measurement Instrumentation for Multsprocessor Computers. International Symposium on High Performance Computer Systems, E. Gelenbe (editor), Elsevler Science Publishers B.V. (North-Holland), pp. 81-92, 1988.

Kruskal, Clyde P. and Smith, Carl H. On the Notion of Granularity. The Journal of Supercomputing I, pp. 395-408, Kluwer Academic Publishers, Boston, 1988.

Kruskal, Clyde P. and Smith, Carl H. Definitions of Granularity. International Symposium on High Performance Computer Systems, E. Gelenbe leditor), Elsevier Sclence Publishers B.V. (North-Holland), pp. 257-268, 1988.

Podio, Fernando L., Lu Da. Optical Digital Data Disks: A Mathematical Model. To be published.

Wallace, Dolores R. Standards for Software Verification and Validation. IEEE Software (to be published).

Peng, Su, and Wakid, Shukri. A Standard Conformance Tester for X.25 DTE Implementations. IEEE Transactions (to be published).

Kuhn, Richard. Generating Extended State Transitions from Structures Specifications for Distributed Systems. Software Engineering Journal (UK) (to be published). 
Smid, Miles E., and Balenson, David M. Banking Security Standards. Banking Administration Institute (BAI) Paper (to be published).

Moore, Raymond T. Electronically Produced Fingerprint Images. FBI Law Enforcement Bulletin (to be published).

Bowles, Darlene E., Ruhl, Mary K. and McCoy, Wayne H. Using a Standard Formal Description Technique for Modelling Faults and Fault-Tolerance in Systems. Proceedings: 7th Symposium on Reliable Distributed Systems (to be published).

Linn, Richard J. An Overview of Conformance Testing Methodology. Proceedings of the Eighth International Symposium on Protocol Specification, Testing and Verification (to be published).

Nechvatal, James R. Wavefront Matrix Multiplication on a DistributedMemory Multiprocessor. SIAM Journal on Computing (to be published).

Heath, Jim and Welsch, Larry. Difficulties in Parsing SGML. Proceedings for the ACM Conference on Document Processing Systems (to be published).

Bagg, Thomas C. Criteria for Use of CD-ROM. Proceedings of the 11th CODATA Conference (to be published).

Picone, Joseph, Doddington, George R. and Pallett, David S. Phone-Mediated Word Alignment for Speech Recognition Evaluation. IEEE Transactions on Acoustics Speech and Signal Processing (to be published).

Rosenthal, Robert. A Commitment to Open Systems. Proceedings of the New Business Applications of Information Technology Australian Information Technology Council Melbourne, Australia (to be published).

Nielsen, F. H. An Overview of the Office Document Architecture (ODA) Standard Computer Communications (to be published).

Wakid, Shukri A., Holman, Timon and DeWitt, Thomas. The Role of the North American ISDN Users' Forum (NIU-FORUM) In Realizing the Interoperable Integrated Services Digital Network (ISDN). Data Communications (to be published). 


\section{CONFERENCES AND WORKSHOPS}

October 1987 through December 1988

1987

October 5-8 Micrographics Standards Week; sponsored by Association for Information and Image Management

October 5-9 OSI Implementors Workshop

October 20-21 POSIX Implementors Workshop

December 3 Systems Communicating With Systems; cosponsored by General Services Administration

December 14-18 OSI Implementors Workshop

1988

February 1-5 OSI Implementors Workshop

February 25-26 \& 29, ISO/TC97/SC21/WG3 Database

March 1-4

March 24-25 FIPS IRDS Users Workshop

April 6-7 Computer and Telecommunications Security Council

April 19-20 Workshop on Factory Communications; cosponsored by IEEE Industrial Electronics Society, IEEE Computer Society, and NIST

April 25 NIST Workshop on Proposed Applications Portability Profile

May 2-6 OSI Implementors Workshop

May 17 Data Administration Management Association

May 24-25 International Conference on Conformance Testing

May 26 Electronic Data Interchange: Bringing It Together in Government

June 2-3 Electronic Data Interchange Format (EDIF)/Computer-Aided Software Engineering (CASE)

June 8-9 ISDN Users Workshop

June 20 Open Systems Symposium; cosponsored by PRC, X-OPEN and NIST

June 28-July 1 COMPASS '88; cosponsored by IEEE Computer Society Washington Chapter, NIST/NCSL, IEEE Washington Section 
July 8 Workshop on Implementation of Computer Security Act of 1987; cosponsored by NIST, Office of Personnel Management and National Security Agency

July 19-21 ISDN Implementors Workshop

August 22-26 OSI Implementors Workshop

September 22-23 POSIX Workshop

September 27-29 ISDN Users and Implementors Workshop

October 5 POSIX Workshop

October 11-14 Micrographics Standards Week; sponsored by Association for Information and Image Management

October 13-14 Workshop on Implementation of Computer Security Act

October 24-27 Conference on Software Maintenance 1988

(CSM-88); cosponsored by IEEE, DPMA, ACM-SIGSOFT, SMA, and AWC

November 9-10 POSIX Workshop

November 15 Digital Image Forum; cosponsored by Computer Sciences Corporation

December 12-16 OSI Implementors Workshop 


\section{PLANNED CONFERENCES AND WORKSHOPS}

1989

January 17-20 ISDN Users' and Implementors' Workshops

January 24 POSIX Workshop

January 25-27 Invitational Workshop on Data Integrity; cosponsored by IEEE Computer Society Technical Committee

February 28-March 2 Software Defects: Prevention, Detection and Cure; cosponsored by National Security Industrial Association, National Aeronautics \& Space Administration, Library of Congress, American Society for Quality Control, Society for Software Quality, American Institute of Aeronautics, and Electronics Industries Association

March 1-2 GOSIP Users' Workshop

March 13-15 Joint ISDN Users' Workshop and ISDN Implementors' Workshop of the North American ISDN Users' Forum

March 13-17 OSI Implementors Workshop

May 3 Data Administration Management Association Annual Symposium; cosponsored by National Capital Region DAMA and FEDMUG

May 22 Applications Portability Profile (APP) Workshop

June 12-16 OSI Implementors Workshop

June 14-16 Joint ISDN Users' Workshop and ISDN Implementors' Workshop of the North American ISDN Users' Forum

August 24 Interfaces: Systems and People Working Together; cosponsored with Association for Computing Machinery (ACM)

September 11-15 OSI Implementors Workshop

November 1-2 Federal ShowCASE '89; cosponsored by IEEE Computer Society

December 11-15 OSI Implementors Workshop 


\section{TALKS}

During the past year, NCSL staff members presented papers and gave talks to a large number of external organizations, including the following:

A ACM/NBS Annual Technical Symposium American Meteorological Society/4th International Conference on Interactive and Information Processing Systems

American National Standards Institute American Society of Mechanical Engineers

American Society for Industrial Security

American Society for Information Science

American Voice Input/Output Society

Association for Computing Machinery

Association of Technical Information

Australian Information Technology Council

B Bell Communications Research

Bureau of Printing and Engraving

C CALS Workshops

Canadian USER/Group Annual Conference

Compass ' 88 Program Committee

Compass ' 88 Tutorial Committee

COMPASS Third Annual Conference on Computer Assurance

COMPSTAN ' 88

Computer and Network Security ' 88

Computer Networking Symposium

Computer Sciences Corporation

Computer Security Institute

Conference on Computer Standards

Corporation for Open Systems

County Clerks Association of the State of California

D DARPA

Data Administration Management Association

Defense \& Government Computer Graphics Conference

Department of Defense

Department of Health and Human Services

E EDPAA 18th Annual Computer, Audit and Control Conference

EDP Auditors Association

EFOC/LAN

Eleventh International Fiber Optics and Local Area Networks Conference

Enterprise Networking Event

EPOC-LAN 88 Information Gatekeepers 
F Federal ADP Users Group

Federal Computer Conference

Federal Coordinator for Meteorological Services and Supporting Research

Federal Data Management Users Group

Federal Office Automation Conference

Federal Software Maintenance Group

Fourth International Conference on Modelling Techniques and Tools for

Computer Performance Evaluation

G George Washington University

H Hawaii Intergovernmental Information Processing Council

I IBM/DEC Users Conference

IEEE

IEEE Computer Society

IEEE Infocom Conference

IEEE/USAB Committee on Communications and Information Policy

Information Systems Security Association

Interagency Committee on Information Resources Management

Internal Revenue Service

International CODATA Conference

International Conference on Formal Description Techniques

International Data Corporation

International Symposium on Interoperable Information Systems

International Symposium on Protocol Specification, Testing and Verification

International Workshop on Computer-Aided Software Engineering

L Los Alamos National Laboratory

M MAP/TOP Users Group

Meadowbrook Workshop on Evaluation of High Performance Computers MITRE Corp.

N NASA Fourth Annual AIS Conference

National Aeronautics and Space Administration

National Archives and Records Administration

National Computer Graphics Association

National Computer Security Center

National Computer Security Conference

National Election Conference

National Institute for Software Quality and Productivity

National Security Industrial Association Software Quality and Reliability

Committee

Naval Medical Command

NIST Workshop for Implementors/OSI

NIST Applications Portability Profile Workshop 
O Open Software Foundation

OSI Solutions for Today

P Pittelli \& Partners

POSIX Implementors Workshop

S Sixth International Conference on Entity-Relationship Approach Society of Manufacturing Engineers

Software Maintenance Conference

Software Management Workshop

Software Risk Management Conference

Symposium on Protocol Specification, Testing and Verification

Symposium on Reliable Distribution Systems

Syracuse University

T Task Force on EP

U UNIEXPO

United States Army Information Systems Software Center

United States Department of Agriculture (UNIX Conference)

University of Maryland

Urban Regional Information Systems Association

W Washington Operations Research/Management Science Council

V Virginia Polytechnic Institute

X X/OPEN 


\section{ELECTRONIC BULLETIN BOARDS}

NCSL operates four electronic bulletin boards for information exchange:

Information about microcomputers and their

(301) 948-5717

applications and computer security

and $948-5718$

Information about data management activities and applications

(301) 948-2048

and 948-2059

Information about Open Systems

(301) $869-8630$

Interconnection standards activities

Information about the North American

(301) 975-5685

Integrated Services Digital Network

and 975-2908

(ISDN) Users' Forum

NIST operates the following bulletin board:

Information about the Computer-Aided Acquisition

(301) 921-9842 and Logistic Support (CALS) Program

Users can reach the bulletin boards by dialing the numbers listed above.

Terminals should have the following capabilities:

ASCII, 300 or 1200 baud, 8 or 7 bits, even or no parity, 1 stop bit.

If a connection is not established at the end of two rings or if the line is busy, hang up and try again.

After "CONNECT" strike the carriage return twice and the system will be accessed.

The system will now guide you through the bulletin board by asking key questions and providing helpful menus. 


\title{
USER GROUPS SPONSORED BY NCSL
}

Federal Data Management Users Group (FEDMUG): meets three or four times a year to share information on data administration and management.

\section{CONTACT: Dan Benigni}

A-266 Technology Building

National Institute of Standards and Technology

Gaithersburg, Md. 20899

Telephone: (301) 975-3266

Federal Software Maintenance Group (FEDMAIN): meets several times a year to exchange information on software techniques, methodologies, and tools.

\author{
CONTACT: Wilma Osborne \\ B-266 Technology Building \\ National Institute of Standards and Technology \\ Gaithersburg, Md. 20899 \\ Telephone: (301) 975-3339
}

MIST Workshop for Implementors of Open Systems Interconnection: meets five times a year to discuss detailed implementation specifications for Open Systems Interconnection Standards.

\section{CONTACT: Tim Boland}

B-217 Technology Building

National Institute of Standards and Technology

Gaithersburg, Md. 20899

Telephone: (301) 975-3608

\section{Government Open Systems Interconnection Users Committee sponsors} workshops and seminars to discuss the government's implementation of OSI standards.

\section{CONTACT: Gerry Mulvenna}

B-217 Technology Building

National Institute of Standards and Technology

Gaithersburg, Md. 20899

Telephone: (301) 975-3631 
Joint ISDN Users' Workshop and ISDN Implementors' Workshop of the North American ISDN Users' Forum: meets four time a year to address application requirements and to develop application profiles for ISDN products and services.

CONTACT: Steve Recicar

A-216 Technology Building

National Institute of Standards and Technology

Gaithersburg, Md. 20899

Telephone: (301) 975-2937

Applications Portability Profile/POSLX Workshops: meet to discuss the development of an architectural approach to applications portability and to review proposed revisions to the POSIX Standard.

CONTACT: James Hall

B-266 Technology Building

National Institute of Standards and Technology

Gaithersburg, Md. 20899

Telephone: (301) 975-3273 


\section{FEDERAL INFORMATION PROCESSING STANDARDS}

\section{Approved, Revised, and Withdrawn}

1988

FIPS NO. TITLE

DATE

FIPS 4-1 Representation for Calendar Date and Ordinal Date for

88 Jan 07 Information Interchange (ANSI X3.30-1985) (Revision)

FIPS 20 WITHDRAWN

88 Aug 23

FIPS 24 WITHDRAWN

88 Aug 23

FIPS 37 WITHDRAWN

88 Feb 22

FIPS 46-1 Data Encryption Standard (Revision/Reaffirmed)

88 Jan 22

FIPS 58-1 Representations of Local Time of the Day for Information Interchg (ANSI X3.43-1986) (Revision)

88 Jan 27

FIPS 91 WITHDRAWN

$88 \mathrm{Feb} 22$

FIPS 98 WITHDRAWN

88 Aug 24

FIPS 132 Guideline for Software Verification and Validation Plans (ANSI/IEEE 1012-1986)

*FIPS 133 Coding and Modulation Requirements for 2,400 Bit/Second Modems

86 Jun 02

*FIPS 134-1 Coding and Modulation Requirements for 4800 Bit/Second Modems

88 Nov 04

*FIPS 135 Coding and Modulation Requirements for Duplex $9600 \mathrm{Bit} / \mathrm{Second}$ Modems

81 March

*FIPS 136 Coding and Modulation Requirements for Duplex 600 and $1200 \mathrm{Bit} / \mathrm{Second}$ Modems

80 Jun 16

*FIPS 137 Analog to Digital Conversion of Voice by 2,400

Bit/Second Linear Predictive Coding

84 Nov 28

*FIPS 138 Electrical Characteristics of Balanced Voltage

Digital Interface Circuits

*FIPS 139 Interoperability and Security Requirements for Use of the Data Encryption Standard in the Physical Layer of Data Communications 
FIPS NO. TITLE

DATE

*FIPS 140 General Security Requirements for Equipment Using the Data Encryption Standard

82 Apr 14

*FIPS 141 Interoperability and Security Requirements for Use of the Data Encryption Standard with

CCITT Group 3 Facsimile Equipment

85 Apr 04

*FIPS 142 Electrical Characteristics of Unbalanced Voltage

Digital Interface Circuits

80 Jan 31

*FIPS 143 General Purpose 37-Position 9-Position Interface

Between Data Terminal Equipment and Data

Circuit-Terminating Equipment

85 Jun 10

*FIPS 144 Data Communication Systems and Services User-

Oriented Performance Parameters

85 May 28

-FIPS 145 Group 2 Facsimile Apparatus for Document Transmission

$81 \mathrm{March}$

FIPS 146 Government Open Systems Interconnection Profile (GOSIP)

88 Aug 24

-FIPS 147 Group 3 Facsimile Apparatus for Document Transmission

81 Aug 19

*FIPS 148 Procedures for Document Facsimile Transmission

(EIA-RS-466)

82 Apr 14

*FIPS 149 General Aspects of Group 4 Facsimile Apparatus

(EIA-536-1988)

88 Nov 04

*FIPS 150 Facsimile Coding Schemes and Coding Control

Functions for Group 4 Facsimile Apparatus

(EIA-538-1988)

88 Nov 04

FIPS 151 POSIX: Portable Operating System Interface for

Computer Environments (IEEE 1003.1/Draft 12)

88 Sept 12

FIPS 152 Standard Generalized Markup Language (SGML)

(ISO 8879-1986)

88 Sept 26

FIPS 153 Programmer's Hierarchical Interactive Graphics

System (PHIGS) (ANSI X3.144-1988)

88 Oct 14

*FIPS 154 High Speed 25-Position Interface for Data Terminal

Equipment and Data Circuit-Terminating

Equipment (EIA-530-1987)

88 Nov 04

*FIPS 155 Data Communication Systems and Services User-

Oriented Performance Measurement Methods

(ANSI X3.141-1987)

88 Nov 04

*Former FED-STDS redesignated as FIPS. 


\section{FIPS PUBLICATIONS LIST BY FIPS NUMBER}

\section{December}

FIPS NO. CATEGORY TITLE-DATE

0

$1-2$

2-1

3-1

4-1

5-2

6-3

7

8-5

9

(1) P General Description of FIPS Register 68 Nov 01

(2\&3) S Code for Information Interchange, Its

Representations, Subsets, and Extensions

(ANSI X3.4-1977, X3.32-1973, X3.41-1974)

84 Nov 14

(2) S Perforated Tape Code for Information Inter-

change (ANSI X3.6-1965/R1983)

84 Nov 14

(2) S Recorded Magnetic Tape for Information Inter-

change (800 CPI, NRZI) (ANSI X3.22-1973)

73 June 30

(4) S Representation for Calendar Date and Ordinal

Date for Information Interchange (ANSI X3.30-1985)

88 Jan 27

(4) S Codes for the Identification of the States, the

District of Columbia and the Outlying Areas of

the United States, and Associated Areas

87 May 28

(4) S Counties and County Equivalents of the States of

the U.S. \& District of Columbia

79 Dec 15

10

WITHDRAWN

1

(4) S Metropolitan Statistical Areas (MSAs) (Including

CMSAs, PMSAs, and NECMAs)

84 Oct 31

4

(4) S Congressional Districts of the U.S.

69 Nov 14

2

Category Key: (1) General Publications (2) Hardware Standards/guidelines (3) Software Standards/guidelines (4) Data Standards/guidelines (5) ADP Operations Standards/guidelines (6) Related Telecommunications Standards (7) Conformance Tests S-Standard G-Guideline P-Program Information Document T-Conformance Tests 
10-3 (4) $S$ Countries, Dependencies, Areas of Special Sovereignty, and Their Principal Admin. Divs. $84 \mathrm{Feb} 09$

11-2 (3) G Guideline: American National Dictionary for Inform.

Processing Systems (X3/TR-1-82)

83 May 09

(2) S Rectangular Holes in Twelve-Row Punched Cards

(ANSI X3.21-1967/R1980)

71 Oct 01

(2) S Hollerith Punched Card Code (ANSI X3.26-1980)

80 Dec 24

(6) S Bit Sequencing of Code for Information Interchange in Serlal-By-Bit Data Transmission (ANSI X3.15-1976/R1983)

77 Sept 01

(6) S Character Structure and Char. Parity Sense for Serial-By-Bit Data Communication in the Code for Inform. Interchg. (ANSI X3.16-1976/R1983) 77 Sept 01

18-1

(6) S Character Structure and Char. Parity Sense for Parallel-By-Bit Data Communication in the Code for Inform. Interchg. (ANSI X3.25-1976/R1983) 77 Sept 01

(4) G Catalog of Widely Used Code Sets $85 \mathrm{Jan} 07$

WITHDRAWN

(3) $\mathrm{S}$ COBOL (ANSI X3.23-1985)

$86 \mathrm{Mar} 18$

Category Key: (1) General Publications (2) Hardware Standards/guidelines (3) Software Standards/guidelines (4) Data Standards/guidelines (5) ADP Operations Standards/guidelines (6) Related Telecommunications Standards (7) Conformance Tests s-Standard G-Guideline P-Program Information Document $\mathbf{T}$-Conformance Tests 
FIPS NO. CATEGORY TITLE-DATE

22-1

23

24

25

26

27

28

29-2

30

31

32-1

33-1

(6) S Synchronous Signaling Rates Between Data

Terminal and Data Communication Equip.

(ANSI X3.1-1976)

77 Sept 01

WITHDRAWN

1

WITHDRAWN

1

(2) S Recorded Magnetic Tape for Information Interchg.

(1600 CPI, Phase Encoded) (ANSI X3.39-1973)

73 June 30

(2) S One-Inch Perforated Paper Tape for Information

Interchange (ANSI X3.18-1967/R1974\&1982)

73 June 30

(2) S Take-Up Reels for One-Inch Perforated Tape for

Information Interchg. (ANSI X3.20-1967/R1982)

73 June 30

(4) P Standardization of Data Elements and Repre-

sentations

73 Dec 05

(1\&3) P Interpretation Procedures for Federal Information

Processing Standards for Software

87 Sept 14

(3) S Software Summary for Describing Computer Programs

and Automated Data Systems

74 June 30

(5) G Guidelines for Automatic Data Processing Physical

Security and Risk Management

74 June--

(2) S Character Sets for Optical Char. Recognition (OCR)

(ANSI X3.2-1970/R1976,X3.17-1981,X3.49-1975/

R1982)

82 June 25

(2) S Character Set for Handprinting (ANSI X3.45-1982)

84 Nov 05

Category Key: (1) General Publications (2) Hardware Standards/guldelines (8) Software Standards/guidelines (4) Data Standards/guidelines (5) ADP Operations Standards/guidelines (6) Related Telecommunications Standards (7) Conformance Teats

8-Standard G-Guideline P-Program Information Document $\mathbf{T}$-Conformance Tests 
34 (1) P Guide for the Use of International System of Units (SI) in Federal Information Processing Standards Publications

75 Jan 01

(3) G Guidelines for Documentation of Computer Programs and Automated Data Systems

76 Feb 15

(5) G Glossary for Computer Systems Security 76 Feb 15

(2) G Guideline for Optical Character Recognition Forms 76 May 01

(5) G Computer Security Guidelines for Implementing the Privacy Act of 1974

75 May 30

(5) G Guidelines for Benchmarking ADP Systems in the Competitive Procurement Environment

77 May 15

(4) G Guide for the Development, Implementation \& Maintenance of Standards for the Representation of Computer Processed Data Elements 76 Sept 30

(5) S Data Encryption Standard 88 Jan 22

Guidelines on Evaluation of Techniques for Automated Personal Identification

77 Apr 01

Category Key: (1) General Publications (2) Hardware Standards/guidelines (3) Software Standards/guidelines (4) Data Standards/guidelines (5) ADP Operations Standards/guidelines (6) Related Telecommunications Standards (7) Conformance Tests S-Standard G-Guideline P-Program Information Document T-Conformance Tests 
49 (5) G Guideline on Computer Performance Management:

An Introduction

77 May 01

50

(2) S Recorded Magnetic Tape for Information Interchange, $6250 \mathrm{cpi}(246 \mathrm{cpmm})$, Group Coded Recording

(ANSI X3.54-1976)

$78 \mathrm{Feb} 01$

51

(2) S Magnetic Tape Cassettes for Information Interchange

(3.810 $\mathrm{mm}$ [0.150 in] Tape at $32 \mathrm{bpmm}$ [800bpi],PE)

(ANSI X3.48-1977)

$78 \mathrm{Feb} 01$

(2) S Recorded Magnetic Tape Cartridge for Inform. Interchange., 4-Track, $6.30 \mathrm{~mm}$ (1/4in), 63 bpmm (1600 bpi), Phase Encoded (ANSI X3.56-1977) 78 July 15

(3) S Transmittal Form for Describing Computer Magnetic Tape File Properties

78 Apr 01

(2) S Computer Output Microform (COM) Formats and

Reduction Ratios, $16 \mathrm{~mm}$ and $105 \mathrm{~mm}$

78 July 15

(4) G Guideline: Codes for Named Populated Places Primary County Divisions, and Other Locational Entities of the United States and Outlying Areas

87 Jan 16

(4) G Same as 55DC except without codes

$87 \mathrm{Feb} 03$

(5) G Guideline for Managing Multivendor Plug-Compatible ADP Systems

78 Sept 15

(5) G Guidelines for the Measurement of Interactive

Computer Service Response Time and Turnaround

Time

78 Aug 01

Category Key: (1) General Publications (2) Hardware Standards/guidelines (3) Software Standards/guidelines (4) Data Standards/guidelines (5) ADP Operations Standards/guidelines (6) Related Telecommunications Standards (7) Conformance Tests S-Standard G-Guideline P-Program Information Document T-Conformance Tests 
58-1 (4) S Representations of Local Time of the Day for Information Interchange (ANSI X3.43-1986) 88 Jan 27

(4) S Representations of Universal Time, Local Time Differentials, and United States Time Zone References for Information Interchange (ANSI X3.51-1975) $79 \mathrm{Feb} 01$

$60-2$

(2) S I/O Channel Interface 83 July 29

61-1 (2) S Channel Level Power Control Interface 82 July 13

(2) S Operational Specification for Magnetic Tape Subsystems

79 Feb $161+F$.R. notice

$63-1$

(2) S Operational Specification for Variable Block Rotating Mass Storage Subsystems 83 Apr 14

63-1 SUPPLEMENT Additional Operational Specs for VBRMSS 83 Apr 14

(3) G Guidelines for Documentation of Computer Programs and Automated Data Systems for the Initiation Phase 79 Aug 01

(5) G Guideline for Automatic Data Processing Risk Analysis 79 Aug 01

(4) S Standard Industrial Classification (SIC) Codes 79 Aug 15

(2) G Guideline for Selection of Data Entry Equipment 79 Sept 30 
FIPS NO. CATEGORY TITLE-DATE

69-1

70-1

71

72

73

74

75

76

77

78

79

80

81

(3) S FORTRAN (ANSI X3.9-1978)

85 Dec 24

(4) S Representation of Geographic Point Locations for

Information Interchange (ANSI X3.61-1986)

86 Nov 14

(6) S Advanced Data Communication Control Procedures

(ADCCP) (ANSI X3.66-1979)

80 May 14

(5) G Guidelines for Measurement of Remote Batch

Computer Service

80 May 01

(5) G Guidelines for Security of Computer Applications

80 June 30

(5) G Guidelines for Implementing and Using the NBS Data

Encryption Standard

81 Apr 01

(5) G Guideline on Constructing Benchmarks for ADP System

Acquisitions

80 Sept 18

(3) G Guideline for Planning and Using a Data Dictionary

System

80 Aug 20

(3) G Guideline for Planning and Management of Database

Applications

80 Sept 01

(6) G Guideline for Implementing Advanced Data Communication Control Procs (ADCCP)

80 Sept 26

(3) S Magnetic Tape Labels and File Structure for Informa-

tion Interchange (ANSI X3.27-1978)

80 Oct 17

WITHDRAWN

1

(5) S DES Modes of Operation

80 Dec 02

1

Category Key: (1) General Publications (2) Hardware Standards/guidelines (3) Software Standards/guidelines (4) Data Standards/guidelines (5) ADP Operations Standards/guidelines (6) Related Telecommunications Standards (7) Conformance Tests

S-Standard G-Guideline P-Program Information Document T-Conformance Tests 
82

83

84

85

86

87

88

89

90

91

92

93
(2) G Guideline for Inspection and Quality Control for Alphanumeric Computer-Output Microforms (AIIM (NMA) MS1-1980)

80 Sept 26

(5) G Guideline on User Authentication Techniques for Computer Network Access Control 80 Sept 29

(2) S Microfilm Readers (ANSI/AIIM(NMA) MS20-1979) 80 Oct 31

(2) S Optical Character Recognition (OCR) Inks (ANSI X3.86-1980/R1987)

80 Nov 07

(2) S Additional Controls for Use with Amer. Natl. Std. Code for Inform. Interchg. (ANSI X3.64-1979)

81 Jan 29

(5) G Guidelines for ADP Contingency Planning

81 Mar 27

(3) G Guideline on Intregity Assurance and Control in Database Administration

81 Aug 14

(2) S Optical Character Recognition (OCR) Character Positioning (ANSI X3.93M-1981) 81 Sept 04

(2) G Guideline for Optical Character Recognition (OCR) Print Quality (ANSI X3.99-1983)

83 Sept 29

WITHDRAWN

(4) G Guideline for Standard Occupational Classification

(SOC) Codes

$83 \mathrm{Feb} 24$

(2) S Parallel Recorded Magnetic Tape Cartridge for Information Interchange, 4-Track, $6.30 \mathrm{~mm}$ (1/4 in), 63 bpmm (1600 bpi), Phase Encoded (ANSI X3.721981/R1987)

82 June 29

Category Key: (1) General Publications (2) Hardware Standards/guidelines (3) Software Standards/guidelines (4) Data Standards/guidelines (5) ADP Operations Standards/guidelines (6) Related Telecommunications Standards (7) Conformance Tests

s-Standard G-Guideline P-Program Information Document T-Conformance Tests 
94 (2) G Guideline on Electrical Power for ADP Installations 83 Sept 21

(4) S Codes for the Identification of Federal and Federally-

Assisted Organizations

82 Dec 23

(5) G Guideline for Developing and Implementing a Charging System for Data Processing Services 82 Dec 06

(2) S Operational Specifications for Fixed Block Rotating Mass Storage Subsystems $83 \mathrm{Feb} 04$

(3) G Guideline: A Framework for the Evaluation and Comparison of Software Development Tools 83 Mar 31

(6) S Interface Between Data Terminal Equipment (DTE) and Data Circuit-Terminating Equipment (DCE) for Operation with Packet-Switched Data Communications Networks 83 July 06

101 (3) G Guideline for Lifecycle Validation, Verification, and Testing of Computer Software 83 June 06

(5) G Guideline for Computer Security Certification and Accreditation 83 Sept 27

(4) S Codes for the Identification of Hydrologic Units in the United States and the Caribbean Outlying Areas (USGS/CIRCULAR \#878-A\& ANSI X3.145-1986) 83 Nov 15

(4) S ANS Codes for the Representation of Names of Countries, Dependencies, and Areas of Special Sovereignty for Information Interchange 86 May 12

Category Key: (1) General Publications (2) Hardware Standards/guidelines (3) Software Standards/guidelines (4) Data Standards/guidelines (5) ADP Operations Standards/guidelines (6) Related Telecommunications Standards (7) Conformance Tests S-Standard G-Guideline P-Program Information Document $\mathbf{T}$-Conformance Tests 
105 (3) G Guideline for Software Documentation Management 84 June 06

106 (3) G Guideline on Software Maintenance 84 June 15

107

(2\&3) S Local Area Networks: Baseband Carrier Sense Multiple Access with Collision Detection Access Method and Physical Layer Specifications and Link Layer Protocol (ANSI/IEEE 802.2\&802.3) 84 Oct 31

(2) S Alphanumeric Computer Output Microform Quality Test Slide (AIIM MS28-1983) 84 Nov 05

(3) S Pascal (ANSI/IEEE 770X3.97-1983) 85 Jan 16

(3) G Guideline for Choosing a Data Management Approach $84 \mathrm{Dec} 11$

111 (2) $S$ Storage Module Interfaces (w/extens. for enhanced storage module interfaces) (ANSI X3.91M-1982) 85 Apr 18 85 May 30

(5) S Computer Data Authentication 85 May 30

(2) S $200 \mathrm{~mm}$ (8in) Flexible Disk Cartridge Track Format Using Two-Frequency Modulation Recording at 6631 bprad on One Side - 1.9 tpmm (48 tpi) for Information Interchange (ISO 5654/2) 85 Sept 30

(2) S $200 \mathrm{~mm}$ (8in) Flexible Disk Cartridge Track Format Using Modifled Frequency Modulation Recording at 13262 bprad on Two-Sides - 1.9 tpmm (48 tpi) for Information Interchange (ISO 7065/2) 85 Sept 30

Category Key: (1) General Publications (2) Hardware Standards/guidelines (3) Software Standards/guidelines (4) Data Standards/guidelines (5) ADP Operations Standards/guidelines (6) Related Telecommunications Standards (7) Conformance Tests S-Standard G-Guldeline P-Program Information Document T-Conformance Tests 
116 (2) $\mathrm{S} 130 \mathrm{~mm}$ (5.25 in) Flexible Disk Cartridge Track Format Using Two-Frequency Recording at 3979 bprad on One Side - $1.9 \mathrm{tpmm}$ (48 tpi) for Information Interchange (ISO 6596/2) 85 sept 30

(2) $\mathrm{S} 130 \mathrm{~mm}$ (5.25 in) Flexible Disk Cartridge Track Format Using Modified Frequency Modulation Recording at 7958 bprad on two sides $-1.9 \mathrm{tpmm}$ ( $48 \mathrm{tpi}$ ) for Information interchange (ISO $7487 / 3$ ) 85 Sept 30

118 (3) S Flexible Disk Cartridge Labelling and File Structure for Information Interchange (ISO 7665) 85 Sept 30

(3) S Ada (ANSI/MIL-STD-1815A-1983) 85 Nov 08

121 (2\&3) S Videotex/Teletext Presentation Level Protocol Syntax (North American PLPS) (ANSI X3.110-1983/CS T500-1983)

86 May 06

122 (7) $\mathrm{T}$ Conformance Tests for FIPS PUB 100 Version of CCITT 1980 Recommendation X.25, etc. 86 May 28

(3) G Guideline on Functional Specifications for Database Management Systems 86 Sept 30

(3) S Specification for a Data Descriptive File for Information Interchange (DDF) (ANSI/ISO 8211-1985) 86 Sept 19 MUMPS (ANSI/MDC X11.1-1984) 86 Nov 4

(3) S Database Language NDL (ANSI X3.133-1986) 87 Mar 10

Category Key: (1) General Publications (2) Hardware Standards/guidelines (3) Software Standards/guidelines (4) Data Standards/guidelines (5) ADP Operations Standards/guidelines (6) Related Telecommunications Standards (7) Conformance Tests S-Standard G-Guideline P-Program Information Document T-Conformance Tests 
127 (3) S Database Language SQL (ANSI X3.135-1986) 87 Mar 10

128 (3) $\mathrm{S}$ Computer Graphics Metafile (CGM) (ANSI X3.122-

1986)

87 Mar 16

129 (2) S Optical Character Recognition (OCR) - Dot Matrix

Character Sets for OCR-MA (ANSI X3.111-1986)

87 May 06

130 (2) S Intelligent Peripheral Interface (IPI) (ANSI X3.129-

1986, X3.130-1986, X3.132-1987, and X3.147-1987)

87 July 16

131 (2) S Small Computer System Interface (SCSI) (ANSI X3.131-

1986)

87 July 16

132 (3) G Guideline for Software Verification and Validation

Plans (ANSI/IEEE 1012-1986)

87 Nov 19

*133 (6) S Coding and Modulation Requirements for 2,400 Bit/

Second Modems

86 June 02

*134-1

(6) S Coding and Modulation Requirements for 4800 Bit/

Second Modems

88 Nov 04

*135 (6) S Coding and Modulation Requirements for Duplex 9600

Bit/Second Modems

81 March

*136 (6) S Coding and Modulation Requirements for Duplex 600

and $1200 \mathrm{Bit} /$ Second Modems

80 June 16

*137 (6) S Analog to Digital Conversion of Voice by 2,400 Bit/

Second Linear Predictive Coding

84 Nov 28

*138 (6) S Electrical Characteristics of Balanced Voltage Digital

Interface Circuits

75 Sept 24

*Being printed

Category Key: (1) General Publications (2) Hardware Standards/guidelines (3) Software Standards/guidelines (4) Data Standards/guidelines (5) ADP Operations Standards/guidelines (6) Related Telecommunications Standards (7) Conformance Tests

S-Standard G-Guideline P-Program Information Document T-Conformance Tests 
FIPS NO. CATEGORY TITLE-DATE

*139 (6) S Interoperability and Security Requirements for Use of the Data Encryption Standard in the Physical

Layer of Data Communications

83 Aug 3

*140 (6) S General Security Requirements for Equipment Using the Data Encryption Standard

82 Apr 14

*141 (6) S Interoperability and Security Requirements for Use of the Data Encryption Standard with CCITT

Group 3 Facsimile Equipment

85 Apr 04

* 142 (6) S Electrical Characteristics of Unbalanced Voltage

Digital Interface Circuits

80 Jan 31

*143 (6) S General Purpose 37-Position 9-Position Interface

Between Data Terminal Equipment and Data Circuit-Terminating

Equipment

85 June 10

*144 (6) S Data Communication Systems and Services User-

Oriented Performance Parameters

85 May 28

*145 (6) S Group 2 Facsimile Apparatus for Document Transmis-

sion

$81 \mathrm{March}$

146 (2\&3) S Government Open Systems Interconnection Profile (GOSIP)

88 Aug 24

*147 (6) S Group 3 Facsimile Apparatus for Document Transmission

81 Aug 19

*148 (6) S Procedures for Document Facsimile Transmission

(EIA-RS-466)

82 Apr 14

*149 (6) S General Aspects of Group 4 Facsimile Apparatus

(EIA-536-1988)

88 Nov 04

*Being printed

Category Key: (1) General Publications (2) Hardware Standards/guidelines (3) Software Standards/guidelines (4) Data Standards/guldelines (5) ADP Operations Standards/guidelines (6) Related Telecommunications Standards (7) Conformance Tests

S-Standard G-Guideline P-Program Information Document T-Conformance Tests 
*150 (6) S Facsimile Coding Schemes and Coding Control Functions for Group 4 Facsimile Apparatus (EIA-538-1988) 88 Nov 04

(3) S POSLX: Portable Operating System Interface for Computer Environments (IEEE 1003.1/Draft 12)

88 Sept 12

*152 (3) S Standard Generalized Markup Language (SGML) (ISO 8879-

1986)

88 Sept 26

(3) S Programmer's Hierarchical Interactive Graphics System

(PHIGS) (ANSI X3.144-1988)

88 Oct 14

$* 154$

(6) S High Speed 25-Position Interface for Data Terminal Equipment and Data Circuit-Terminating Equipment

(EIA-530-1987)

88 Nov 04

*155

(6) S Data Communication Systems and Services User-Oriented

Performance Measurement Methods

(ANSI X3.141-1987)

88 Nov 04

*Being printed

Category Key: (1) General Publications (2) Hardware Standards/guidelines (3) Software Standards/guidelines (4) Data Standards/guidelines (5) ADP Operations Standards/guidelines (6) Related Telecommunications Standards (7) Conformance Tests

S-Standard G-Guideline P-Program Information Document T-Conformance Tests 


\section{TELEPHONE ORDERS} Call (703) $487-4650$
TELEX 89-9405 Telecopier (703) 321-8547 Subscriptions: (703) 487-4630

(See reverse side for RUSH and EXPRESS ordering options)

- HANDLING FEE: A handling fee is required for each order except for Express, Rush, Subscription, or Pickup orders.

- SHIPPING: U.S.: Printed reports and microfiche copies are shipped First Class Mail or equivalent.

FOREIGN: Regular service: Printed reports and microfiche copies are shipped surface mail.

Air Mail service to Canada and Mexico: add \$3 per printed report; $\$ .75$ per microfiche copy.

Air Mail service to all other addresses: add $\$ 6$ per printed report; $\$ .75$ per microfiche copy.

SUBSCRIPTIONS and standing orders are sent surface mail; contact NTIS for air mail rates.

\section{Address Information}

PURCHASER: DATE:

\begin{tabular}{ll}
\hline Last Name & First Initial \\
\hline$\overline{\text { Title }}$ \\
\hline Company/Organization \\
\hline Address
\end{tabular}

\section{City/State/ZIP}

Attention

Telephone number

\section{Method of Payment}

Charge my NTIS Deposit Account _- _ _ -

Charge my $\square$ Amer. Express $\square$ VISA $\square$ MasterCard

Account No. Exp.

Signature:

(Required to validate all orders)
DTIC Users Code:

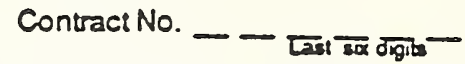
SHIP TO (Enter ONLY if different from purchaser):
Last Name
First Initial

Title

Company/Organization

Address

City/State/ZIP

Attention

Telephone number

Check/Money order enclosed for \$

Please bill ADD $\$ 7.50$ per Order. (See below for restrictions) ${ }^{\dagger}$

Purchase Order No.

Employer Identification No. $-\ldots---$

\section{Order Selection (For Computer products, see reverse)}

Enter NTIS order number(s) followed by title(s). Group titles after order numbers. (Ordering by title only will delay your order) 1. 2. 3. 4. $\underline{5 .}$ 6. 7. $\angle \mathrm{BAT}$ $\angle B A T$ /BAT /BAT $\angle B A T$ $/ \mathrm{BAT}$ $/ \mathrm{BAT}$

\section{OVER - Order continued on reverse}

+ Billing Service: This service is restricted to U.S. addresses for an additional $\$ 7.50$ per order. Your business employer identification number plus phone number of the office paying the bill are required. A late payment charge will be applied $t$ all billings more than 30 days overdue.

t† Customer Routing Code: NTS can label each item for routing within your organization if you want this service, put your routing code in this box.

\begin{tabular}{|c|c|c|c|c|c|}
\hline & \multicolumn{2}{|c|}{ QUANTITY } & \multirow[b]{2}{*}{$\begin{array}{l}\text { UNIT } \\
\text { PRICE }\end{array}$} & \multirow[b]{2}{*}{$\begin{array}{l}\text { Foreign } \\
\text { Air Mail }\end{array}$} & \multirow[b]{2}{*}{$\begin{array}{l}\text { TOTAL } \\
\text { PRICE }\end{array}$} \\
\hline Customer & $\begin{array}{l}\text { Paper } \\
\text { Copy }\end{array}$ & $\begin{array}{l}\text { Micro- } \\
\text { fiche }\end{array}$ & & & \\
\hline & & & & & \\
\hline & & & & & \\
\hline & & & & & \\
\hline & & & & & \\
\hline & & & & & \\
\hline & & & & & \\
\hline & & & & & \\
\hline \multicolumn{5}{|c|}{ SUBTOTAL From Other Side } & \\
\hline \multicolumn{5}{|c|}{$\begin{array}{l}\text { Regular Sernce Handling Fee per order } \\
\text { (\$3U. S., Canada. Mexico: \$4 others) }\end{array}$} & \\
\hline \multicolumn{5}{|c|}{ Billing $F_{\theta \theta}$ if required $(\$ 7.50)$} & \\
\hline & \multicolumn{4}{|c|}{ GRAND TOTAL } & \\
\hline
\end{tabular}




\section{Order Selection (Cont.)}

\section{Enter the NTS order number(s) or title(s). Group titles after order numbers. (Ordering by title only will delay your order)}

8.

9.

10.

11.

12.

13.

14.

15.

16.

17.

18.

19.

\begin{tabular}{|c|c|c|c|c|c|c|}
\hline & & QUA & VTITY & & & \\
\hline 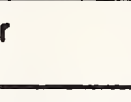 & $\begin{array}{c}\text { Customer } \\
\text { Routing } \pi \\
\end{array}$ & \begin{tabular}{|l} 
Paper \\
Copy \\
\end{tabular} & $\begin{array}{l}\text { Micro- } \\
\text { fiche }\end{array}$ & $\begin{array}{c}\text { UNIT } \\
\text { PRICE } \\
\end{array}$ & $\begin{array}{l}\text { Foreign } \\
\text { Air Mail } \\
\end{array}$ & $\begin{array}{l}\text { TOTAL } \\
\text { PRICE }\end{array}$ \\
\hline$\angle B A T$ & & & & & & \\
\hline$/ \mathrm{BAT}$ & & & & & & \\
\hline$/ B A T$ & & & & & & \\
\hline$\angle B A T$ & & & & & & \\
\hline$/ \mathrm{BAT}$ & & & & & & \\
\hline$/ B A T$ & & & & & & \\
\hline$/ \mathrm{BAT}$ & & & & & & \\
\hline$/ \mathrm{BAT}$ & & & & & & \\
\hline$/ \mathrm{BAT}$ & & & & & & \\
\hline$/ \mathrm{BAT}$ & & & & & & \\
\hline$\angle \mathrm{BAT}$ & & & & & & \\
\hline$/ \mathrm{BAT}$ & & & & & & \\
\hline & & & & & Subtotal & \\
\hline
\end{tabular}

ENTER this amount on the other side of this form.

\section{Computer Products Order Selection}

If you have questions about a particular computer product, please call our Computer Products Support Group at (703) $487-4763$.
Enter the NTIS order number(s) or title(s) of the diskette or magnetic tape products. (Ordering by title only will delay your order)

20.

21.

22.

23.

All magnetic tapes are sent air mail or equivalent service to both U.S. and foreign addresses.

\begin{tabular}{|c|c|c|c|}
\hline \multirow[b]{2}{*}{$\begin{array}{c}\text { Customer } \\
\text { Routing }\end{array}$} & \multicolumn{2}{|c|}{$\begin{array}{c}\text { TAPE DENSITY } \\
(9 \text { track })\end{array}$} & \multirow[b]{2}{*}{$\begin{array}{l}\text { TOTAL } \\
\text { PRICE }\end{array}$} \\
\hline & $1600 \mathrm{bpi}$ & $6250 b \mathrm{pi}$ & \\
\hline & & & \\
\hline & & & \\
\hline & & & \\
\hline & & & \\
\hline & \multicolumn{2}{|c|}{ Subtotal } & \\
\hline
\end{tabular}

ENTER this amount on the other side of this form.
SPECIAL RUSH and EXPRESS ORDERING OPTIONS

Telephone: (800) 336-4700 in Virginia call (703) $487-4700$
RUSH SERVICE: Orders are processed within 24 hours and sent Air Mail or equivalent.

- Pick up at NTIS - $\$ 7.50$ peritem

- Delivery to U.S. addresses - $\$ 10$ per item

EXPRESS SERVICE (U.S. Addresses Only): Orders are processed within 24 hours AND delivered by overnight courier for an additional $\$ 20$ per item 


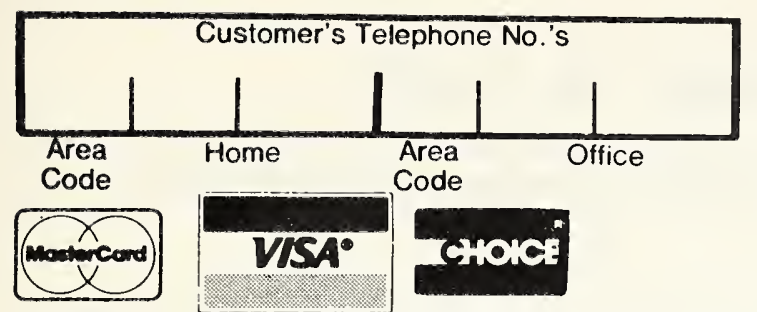

\section{ORDER FORM}

\section{MAIL TO:}

Superintendent of Documents U.S. Government Printing Office Washington, DC 20402-9325 Date

Customer Order Number

Credit

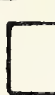

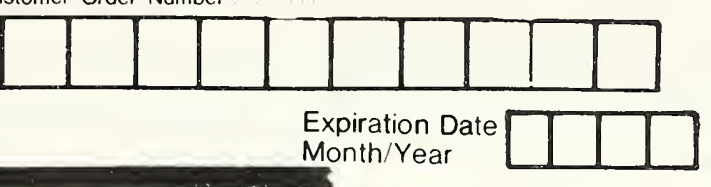

FOR OFFICE USE ONLY QUANTITY CHARGES Publications Subscriptions

Special shipping charges International handling Special charges. OPNA.

\begin{aligned} & \hline UPNS \\ & Balance Due \\ & Discount \\ & Refund \end{aligned}

Deposit Account Number

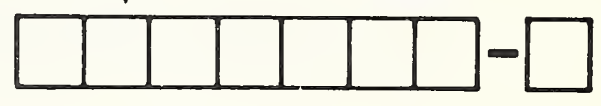

TO PLACE YOUR ORDER BY PHONE, CALL OUR ORDER DESK AT 202-783-3238, MONDAY THROUGH FRIDAY, 8-4.0OP.M., EASTERN TIME

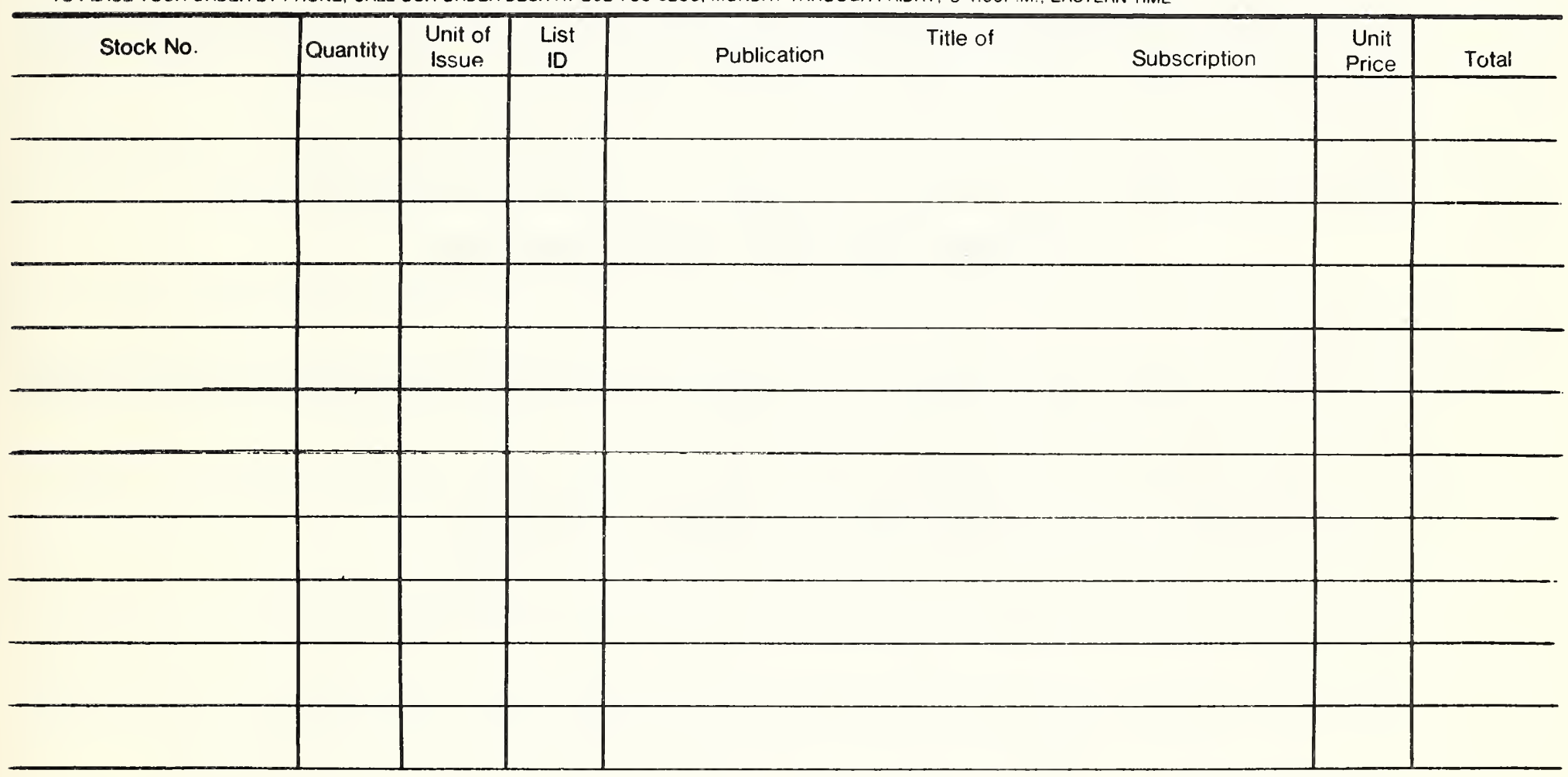

TOTAL ENCLOSED \$

EA Each - single copy

KT Kit of multiple items in a special container

PD Pad containıng multiple sheets

PK Package containing multiple copies

SE Set of multiple items

SU Subscription 


\section{INFORMATION CONCERNING YOUR ORDER OR INQUIRY}

Thank you for your interest in U.S. Government publications. If you made a written inquiry, it is returned for your reference. There is no free distribution by this Office, since we are established by law as the sales agency for Government publications. We have indicated the prices of publications currently available, or have provided the information requested to the best of our ability. Unless otherwise noted, prices are for single copies, and all prices are subject to change without notice.

Payment is required in advance of shipment of publications. You may order using check or money order drawn on a bank located in Canada, the United States, or United States Possessions, in U.S. dollars. Make checks/money orders payable to the Superintendent of Documents. Checks returned by the bank as uncollectible are subject to a penalty of up to 10 percent of the amount of the check, with a minimum charge of five dollars $(\$ 5.00)$. You may also order, by using your VISA, MasterCard, Choice or Superintendent of Documents Prepaid Deposit Account. Do not send currency (bills or coins) or postage stamps.

Shipping is by non-priority mail. United Parcel Service. First class and airmail services are available for an additional charge if requested. Please contact us in advance for rates if you desire this service (202-783-3238) and indicate on your order if you desire special postage.

\section{DISCOUNTS:}

With the exception of certain publications and subscriptions, a discount of $25 \%$ from the domestic price is allowed on orders of 100 or more units of issue mailed to a single address. A discount of $25 \%$ from the domestic price is also applicable on orders from bookdealers, for orders of any quantity, mailed to the dealer's business address. (The maximum discount allowable is $25 \%$.)

\section{INTERNATIONAL CUSTOMERS:}

Mailing regulations require special handling for orders mailed to addresses outside the United States or its possessions for which we charge an additional $25 \%$ of the domestic price. Payment is required in advance by one of the methods stated above. You may also remit by UNESCO coupons or by International Postal Money Order, made payable to the Superintendent of Documents. Foreign currency and foreign checks will not be accepted. International customers are allowed the same discounts stated above. All orders must be in English.

Orders are sent via surface mail unless otherwise requested. Should you desire airmail service, please contact us in advance by letter. telephone (202-783-3238), or Telex (\#710-822-9413, ANSWERBACK USGPO WSH) for the total cost of your order

\section{TO ORDER, USE FORM ON REVERSE SIDE}

1 A separate order form must be used for ordering the following: subscription services and publications (which includes single issues of a subscription.)

2. Type or print your complete name and address, home and office telephone numbers, date. order number (if any). Deposit Account Number (if applicable), VISA, MasterCard, or Choice number and expiration date (if applicable). in proper places at the top of the form. If order is to be shipped to another location. enter address at bottom of form

3. When ordering publications, type or print the stock number, unit of issue (see front), quantity, title, price, and total payment enclosed ALLOW A MINIMUM OF FOUR WEEKS FOR DELIVERY (for Internatıonal Orders allow a minımum of eight weeks). Mail original of form to Superintendent of Documents, Government Printing Office, Washıngton, DC 20402-9325

4. When ordering a subscription service, type or print the quantity, title, price, List ID (when available), and total payment enclosed. Allow 2-6 weeks, plus mailing time, for processing. All subscriptions are one year, unless otherwise noted Subscribers will be notified by mail in ample time to renew. Mail onignal of form to Superintendent of Documents, Govemment Printing Office, Washington, DC 20402-9371.

5. When ordering a specific single issue of a subscription, type or print the complete titles of the subscription, the List ID or the stock number of the issue ordered (when avallable), single copy price, and all data pertaining to the requested issue (issue date, volume number, issue number, etc.). ALLOW A MINIMUM OF FOUR WEEKS FOR DELIVERY (for International orders allow a minimum of eight weeks.) Mail original of form to Superıntendent of Documents. Government Printing Office. Washington, DC 20402-9325

6 If the shipment is incorrect, return the shipping documentation for adjustment DO NOT RETURN BOOK UNTIL NOTIFIED TO DO SO. ALL CLAIMS MUST BE SUBMITTED WITHIN SIX MONTHS

7. Retain the green copy for your records

\section{THE FOLLOWING INFORMATION EXPLAINS HOW YOUR REQUEST WAS PROCESSED}

C. We are unable to identify the publication from the information furnished

1.. This publication is not currently available. Please inquire concerning availability and price in 60 days. Inquiries and orders are accepted by mail, telephone (202-783-3238), or Telex (\#710-822-9413; ANSWERBACK USGPO WSH.) Our telephone order desk is staffed from 7:30 A.M. to 4:00 P.M. Monday through Friday (Eastern Time) and will accept your VISA, MasterCard, Choice or Superintendent of Documents Deposit Account order

L... The publication(s), subscription service(s), or single issue(s) of a subscription service you requested is out of print and no longer available from this Office

S... The publication that you requested has been superseded or replaced by another with similar but more recent information. We have noted the new ordering information on your request.

SU.S.GOVERNMENT PRINTING OFFICER:1989-242-200/00010 



